\title{
Differential Roles of Postsynaptic Density-93 Isoforms in Regulating Synaptic Transmission
}

\author{
Juliane M. Krüger, ${ }^{1,2}$ Plinio D. Favaro, ${ }^{1,2}$ Mingna Liu, ${ }^{3}$ Agata Kitlińska, ${ }^{1}$ Xiaojie Huang, ${ }^{1,2}$ Monika Raabe, ${ }^{4}$ \\ Derya S. Akad, ${ }^{1,5}$ Yanling Liu, ${ }^{1}$ Henning Urlaub, ${ }^{4,6}$ Yan Dong, ${ }^{7}$ Weifeng $\mathrm{Xu},{ }^{3}$ and Oliver M. Schlüter ${ }^{1}$ \\ ${ }^{1}$ European Neuroscience Institute, 37077 Göttingen, Germany, ${ }^{2}$ Göttingen Graduate School for Neurosciences and Molecular Biosciences, 37077 Göttingen, \\ Germany, ${ }^{3}$ Picower Institute for Learning and Memory, Department of Brain and Cognitive Sciences, Massachusetts Institute of Technology, Cambridge, \\ Massachusetts 02319, ${ }^{4}$ Max Planck Institute for Biophysical Chemistry, 37077 Göttingen, Germany, ${ }^{5}$ International Max Planck Research School for \\ Neuroscience, 37077 Göttingen, Germany, ${ }^{6}$ Bioanalytics, Department of Clinical Chemistry, 37075 Göttingen, Germany, and Department of Neuroscience, \\ University of Pittsburgh, Pennsylvania 15260
}

In the postsynaptic density of glutamatergic synapses, the discs large (DLG)-membrane-associated guanylate kinase (MAGUK) family of scaffolding proteins coordinates a multiplicity of signaling pathways to maintain and regulate synaptic transmission. Postsynaptic density-93 (PSD-93) is the most variable paralog in this family; it exists in six different N-terminal isoforms. Probably because of the structural and functional variability of these isoforms, the synaptic role of PSD-93 remains controversial. To accurately characterize the synaptic role of PSD-93, we quantified the expression of all six isoforms in the mouse hippocampus and examined them individually in hippocampal synapses. Using molecular manipulations, including overexpression, gene knockdown, $P S D$-93 knock-out mice combined with biochemical assays, and slice electrophysiology both in rat and mice, we demonstrate that PSD-93 is required at different developmental synaptic states to maintain the strength of excitatory synaptic transmission. This strength is differentially regulated by the six isoforms of PSD-93, including regulations of $\alpha$-amino-3-hydroxy-5-methyl-4-isoxazole propionic acid (AMPA) receptor-active and inactive synapses, and activity-dependent modulations. Collectively, these results demonstrate that alternative combinations of N-terminal PSD-93 isoforms and DLG-MAGUK paralogs can fine-tune signaling scaffolds to adjust synaptic needs to regulate synaptic transmission.

\section{Introduction}

$N$-Methyl-D-aspartate (NMDA) receptor (R)-dependent longterm synaptic plasticity involves the recruitment and removal of AMPARs from the postsynaptic density (PSD) (Malinow and Malenka, 2002; Kerchner and Nicoll, 2008). Such dynamic trafficking as well as the basal turnover of AMPARs are regulated by multiple signaling pathways, which are coordinated by signaling scaffolds, particularly the DLG-MAGUK family of proteins (Craven and Bredt, 1998; Sheng and Kim, 2002; Xu et al., 2008; Ryan

Received Jan. 3, 2012; revised Aug. 20, 2013; accepted Aug. 22, 2013.

Author contributions: 0.M.S., J.M.K., H.U., Y.D., and W.X. designed research; 0.M.S., J.M.K., P.D.F., M.L., A.K., M.R., D.S.A., and Y.L. performed research; X.H. contributed unpublished reagents/analytic tools; 0.M.S., J.M.K., P.D.F., M.L., A.K., M.R., D.S.A., Y.L., H.U., and W.X. analyzed data; O.M.S., J.M.K., and Y.D. wrote the paper.

This work was supported by the German Research Foundation through the Collaborative Research Center 889 "Cellular Mechanisms of Sensory Processing" (0.M.S., H.U.), the German Research Foundation Grants SCHL592/4 (0.M.S.) and INST 186/907-1 (H.U.), the European Commission (0.M.S., P.D.F.), the National Institutes of Health, National Institute on Drug Abuse funds, and the Alexander von Humboldt foundation (Y.D.), and the National Institutes of Health, National Institute of Mental Health fund MH080310 (W.X.). This publication reflects the views only of the authors, and the Commission cannot be held responsible for any use which may be made of the information contained therein. The European Neuroscience Institute Göttingen is jointly funded by the Göttingen University Medical School and the Max Planck Society. We thank S. Ott-Gebauer and M. Bremer for excellent technical assistance; Dr. D. Bredt for the PSD-93 mouse line and antibody; Drs. G. Feng and R. Wenthold for DNA constructs; and the AGCT core facility for primer synthesis and DNA sequencing.

The authors declare no competing financial interests.

Correspondence should be addressed to Dr. Oliver M. Schlüter, European Neuroscience Institute, Grisebachstr. 5 , 37077 Göttingen, Germany. E-mail: oschlue@gwdg.de.

DOI:10.1523/JNEUROSCI.0019-12.2013

Copyright $\odot 2013$ the authors $\quad 0270-6474 / 13 / 3315504-14 \$ 15.00 / 0$ and Grant, 2009). The DLG-MAGUKs consist of PSD-93/ Chapsyn-110, PSD-95/synapse associated protein (SAP)90, SAP97, and SAP102 and share the same domain structure of protein interaction modules, including alternative $\mathrm{N}$-terminal domains, three consecutive PSD-95/discs large/zona occludens-1 (PDZ) domains, and a src-homology 3 (SH3) domain linked to guanylate kinase (GK) like domain (Cho et al., 1992; Kistner et al., 1993; Müller et al., 1995; Brenman et al., 1996; Kim et al., 1996; Müller et al., 1996). The DLG-MAGUK isoforms and paralogs differ primarily by alternative N-terminal domains, which are coded for by alternative transcriptional start sites of the four DLG-MAGUK genes (Chetkovich et al., 2002; Parker et al., 2004; Schlüter et al., 2006). These different domains entail these isoforms/paralogs differential regulatory roles in excitatory synaptic transmission and potentially contribute to their evolutionary specialization in cognitive function (Nithianantharajah et al., 2013). For example, in hippocampal neurons, overexpression of N-terminally palmitoylated $\alpha$-isoforms of PSD-95 (PSD-95 $\alpha$ ) or SAP97 $\alpha$ increases AMPAR-mediated synaptic transmission (Schnell et al., 2002; Béique and Andrade, 2003; Ehrlich and Malinow, 2004), whereas RNAi-mediated knockdown or genetic deletion of PSD-95 produces the opposite effect (Nakagawa et al., 2004; Béique et al., 2006; Elias et al., 2006; Schlüter et al., 2006; Carlisle et al., 2008). On the other hand, the $\beta$-isoforms of PSD-95 and SAP97, which express an N-terminal L27 domain, govern activity-dependent enhancement of AMPAR function via 
signaling pathways similar to those that mediate long-term potentiation (LTP) of hippocampal excitatory synapses (Schlüter et al., 2006).

In contrast to PSD-95 and SAP97, much less is known about PSD-93, which possesses more variations in its N-terminal domains. The PSD-93 gene codes six N-terminal domains, including two palmitoylated isoforms, an L27 domain containing isoform, and additionally three unique $\mathrm{N}$-terminal isoforms (Parker et al., 2004). Similar to PSD-95 $\alpha$ and SAP97 $\alpha$, overexpression of PSD-93 $\alpha$ enhances AMPAR-mediated synaptic transmission in organotypic hippocampal slices (Elias et al., 2006). These and other results lead to a thought that PSD-93 and PSD-95 are redundant to some extent with similar cellular functionality. However, studies on the loss of function of all PSD-93 isoforms suggest a different conclusion. In hippocampal slices, genetic deletion of PSD-93 does not affect AMPARs, but RNAimediated knockdown induces a 50\% decrease in AMPARmediated EPSCs (AMPAR EPSCs) (Elias et al., 2006; Carlisle et al., 2008). Furthermore, a decrease in NMDAR EPSCs was observed at cortical synapses in PSD-93 knock-out (KO) mice (Tao et al., 2003), but a similar change is not observed in organotypic hippocampal slices upon RNAi-mediated knockdown of PSD-93 (Elias et al., 2006). Moreover, the phenotypes of PSD-95 and PSD-93 KO mice are opposite. In PSD-95-deficient mice, the induction of LTP is greatly facilitated, whereas long-term depression (LTD) is abolished (Migaud et al., 1998; Béique et al., 2006; Carlisle et al., 2008). In contrast, in PSD-93 KO mice, the threshold for LTP induction is elevated and LTD is normal (Carlisle et al., 2008). These results suggest a different functional identity of PSD-93 from PSD-95, and the seemingly discrepant results may stem from contributions of different N-terminal PSD-93 isoforms in different studies. To address these discrepancies, we examined all these isoforms with a focus on their functionally relevant $\mathrm{N}$ terminus. Our results show that different PSD-93 isoforms played different regulatory roles in excitatory synaptic transmission; they constitute a specific functional repertoire to modulate AMPAR synaptic function, which differs from the function of PSD-95 and SAP97.

\section{Materials and Methods}

Dissociated neuronal cultures. Dissociated hippocampal cultures were prepared from postnatal day $0(\mathrm{P} 0)$ or $\mathrm{P} 1$ mice or Wistar rats of either sex. The hippocampi were dissected and digested for $30 \mathrm{~min}$ at $37^{\circ} \mathrm{C}$ with papain, as previously detailed (Huettner and Baughman, 1986; Schlüter et al., 2006). A total of $10^{5}$ cells per well in a 24 -well plate were plated into DMEM/Ham's F12 (Biochrom) supplemented with 2\% B27 (Invitrogen) and $1 \%$ Glutamax on a poly-D-lysine-coated 24 -well plate. Glial growth was inhibited with FUDR at 4 days in vitro (DIV). The cells were refed every 3-7 d with astrocyte-conditioned culture medium.

Hippocampal slice cultures. Organotypic hippocampal slices were prepared from P7-P9 Wistar rats of either sex, modified from previously published procedures (Stoppini et al., 1991; Schlüter et al., 2006). Briefly, animals were anesthetized with isoflurane, and the hippocampi were dissected in ice-cold sucrose cutting buffer (in mM as follows: 204 sucrose, $26 \mathrm{NaHCO}_{3}, 10$ glucose, $2.5 \mathrm{KCl}, 1 \mathrm{NaH}_{2} \mathrm{PO}_{4}, 4 \mathrm{MgSO}_{4}, 1 \mathrm{CaCl}_{2}$, 4 ascorbic acid). Using a guillotine with a wire frame, $300-\mu \mathrm{m}$-thick slices were cut and transferred into artificial CSF (ACSF) (containing in mM) as follows: $119 \mathrm{NaCl}, 26 \mathrm{NaHCO}_{3}, 20$ glucose, $4 \mathrm{MgSO}_{4}, 2.5 \mathrm{KCl}, 1$ $\mathrm{NaH}_{2} \mathrm{PO}_{4}, 4 \mathrm{CaCl}_{2}$, for recovery. The slices were washed in BME (Biochrom) and plated onto MilliCell (Millipore) culture plate inserts in culture dishes containing BME-based culture medium supplemented with $20 \%$ heat-inactivated horse serum (Biochrom). The slices were incubated at $37^{\circ} \mathrm{C}$ in a $5 \% \mathrm{CO}_{2}$ environment. On DIV 1 , the slices were transferred to $34^{\circ} \mathrm{C}$, and the culture medium was refreshed. On DIV 4, the culture medium was exchanged by BME-based culture medium sup- plemented with $5 \%$ heat inactivated horse serum, and the slices were refed every other day. Where indicated $20 \mu \mathrm{m}$ bicuculline or $20 \mu \mathrm{M}$ bicuculline and $50 \mu \mathrm{M}$ APV was added to the feeding medium after virus infection.

Hippocampal slices. Coronal brain slices $(400 \mu \mathrm{m})$ containing the dorsal hippocampus were prepared from mice of either sex, deeply anesthetized with isoflurane. The brain was rapidly removed in ice-cold NMDG cutting buffer (composition in mM as follows: $45 \mathrm{NMDG}, 0.33 \mathrm{KCl}, 0.5$ $\mathrm{MgCl}_{2}, 0.4 \mathrm{KH}_{2} \mathrm{PO}_{4}, 10 \mathrm{D}-(+)$-glucose, 20 choline bicarbonate, 0.17 $\mathrm{CaCl}_{2}, \mathrm{pH} 7.4$, with $\mathrm{HCl}$ ). Slices were cut on a vibrating microtome recovered in ACSF with $1.3 \mathrm{~mm} \mathrm{MgSO}_{4}$ and $2.5 \mathrm{~mm} \mathrm{CaCl}_{2}$ at $35^{\circ} \mathrm{C}$ for 30 $\mathrm{min}$, and then stored at room temperature until use (1-5 h).

Virus vectors and neuronal transduction. All lentiviral constructs were made from the lentiviral transfer vector FUGW (Lois et al., 2002) and its variant FHUG $+\mathrm{W}$, which additionally contains an RNAi expression cassette driven by an $\mathrm{H} 1$ promoter (Schlüter et al., 2006). For RNAimediated knockdown of rat PSD-93, a hairpin (sh93a) (Ogawa et al., 2008) targeting the sequence GCAAGCTTGTTATTGAAGA was inserted downstream to the $\mathrm{H} 1$ promoter. The constructs sh93b (target sequence: GACTGCCTAGCCAAGGACTTA) and sh93c (target sequence: CTCTATTGTTCGACTGTATAT) driven by the mouse U6 promoter were subcloned into FHUG $+\mathrm{W}$ to replace the $\mathrm{H} 1$ promoter (Elias et al., 2006; Schlüter et al., 2006). A mouse-specific shRNA sh93ms (target sequence: GCACATTAGAATACAAGAC) was driven by the U6 promoter. Dr. Robert J. Wenthold (National Institutes of Health) provided the rat PSD-93 $\alpha 2$ coding sequence (Roche et al., 1999), and Dr. Guoping Feng (Massachusetts Institute of Technology) provided the mouse sequences of PSD-93 $\alpha 1$, PSD-93 $\beta$, PSD-93 $\delta$, and PSD-93 $\varepsilon$ (Parker et al., 2004). The EST clone AW060584 containing the N terminus of PSD-93 $\gamma$ was purchased from Open Biosystems. For studying the effect of overexpression of PSD-93, the eGFP in FUGW was replaced by fusion proteins of C-terminally eGFP-tagged PSD-93 isoforms. To rule out an impact of the C-terminal eGFP on PSD-93 function, bicistronic constructs were generated using the CMV-IRES-GFP cassette of the plasmid pMES (Swartz et al., 2001).

Transduction of neurons in hippocampal slice cultures was achieved by injecting concentrated viral particles into the CA1 pyramidal cell layer on DIV 1 or DIV 2 using a Nanoject II device (Drummond Scientific).

Electrophysiology. Recordings were performed 4-9 d after viral infection from slice cultures, as previously described (Schlüter et al., 2006) or acute hippocampal slices. A single slice was transferred into the recording chamber, which was constantly perfused with oxygenated ACSF (2-3 $\mathrm{ml} / \mathrm{min}$ ) with $4 \mathrm{~mm} \mathrm{MgSO}_{4}$ and $4 \mathrm{mM} \mathrm{CaCl}_{2}$ for slice cultures, and $1.3 \mathrm{~mm}$ $\mathrm{MgSO}_{4}$ and $2.5 \mathrm{~mm} \mathrm{CaCl}_{2}$ for acute slices, respectively. In slice cultures, 1-5 $\mu \mathrm{M}$ 2-chloroadenosine (Biolog) was added to the ACSF to reduce polysynaptic activity; $50 \mu \mathrm{M}$ picrotoxin (Ascent Scientific) was added to block inhibitory transmission and thus to isolate EPSCs. Patch pipettes (open pipette resistance 3-6 MOhm) were filled with intracellular solution containing in mM as follows: $117.5 \mathrm{MeSO}_{3} \mathrm{H}, 10 \mathrm{HEPES}, 17.75 \mathrm{CsCl}$, 10 TEA-Cl, 0.25 EGTA, 10 glucose, $2 \mathrm{MgCl}_{2}$, $4 \mathrm{Na}_{2} \mathrm{ATP}, 0.3 \mathrm{NaGTP}, \mathrm{pH}$ 7.3 , and $290 \mathrm{mOsm}$ for slice cultures; or in mM as follows: 120 cesium gluconate, 20 HEPES, 4 QX-314/Cl, 0.4 EGTA, 5 TEACl, 4 MgATP, 0.3 NaGTP, pH 7.3, and $290 \mathrm{mOsm}$ for acute slices. For pairwise recording, an infected cell and its neighboring uninfected (control) cell were simultaneously recorded using whole-cell voltage-clamp configuration. EPSCs were simultaneously evoked in paired cells by a single bipolar stimulation electrode filled with ACSF (slice culture) or a concentric bipolar stimulating electrode (acute slice). AMPAR EPSCs were recorded at $-60 \mathrm{mV}$. For NMDAR EPSCs, EPSCs were recorded at $40 \mathrm{mV}$, and the amplitude of NMDAR EPSCs was assessed by the amplitude of EPSCs at $60 \mathrm{~ms}$ after the peak currents, a time point at which AMPAR EPSCs are mostly absent. Signals were filtered at $4 \mathrm{kHz}$ and digitalized at $10 \mathrm{kHz}$ using an ITC-18 acquisition board (HEKA). The responses were monitored online and analyzed using custom-written acquisition and analysis software implemented in IGOR Pro (Wavemetrics). For each cell pair (slice culture) or cell (acute slice), a minimum of 40 sweeps was collected and averaged. The stimulation strength was adjusted such that the amplitude of AMPAR EPSCs in control cells was $\sim 100 \mathrm{pA}$. A $5 \mathrm{mV}$ hyperpolarizing step was used to monitor the input and series resistance over the record- 
ing. For mEPSCs, the ratio of $\mathrm{Ca}^{2+} / \mathrm{Mg}^{2+}$ in ACSF was adjusted to 4/1, with $0.5 \mu \mathrm{M}$ TTX and $50 \mathrm{~mm}$ sucrose supplemented. mEPSCs were recorded for 5-15 min, 3 min after break in at 13-17 DIV.

The statistical analysis of electrophysiological data was done with nonparametric tests using the software R Project (R Foundation of Statistical Computing). Comparison between pairs of control and infected cell responses was analyzed using the Wilcoxon Signed-Rank test. Averages of ratios of infected and uninfected cell pairs were calculated after logarithmic transformation and presented as back-transformed mean \pm SEM. For nonpaired measures, the Wilcoxon Mann-Whitney two-sample rank test was used. Multiple groups were compared with the KruskalWallis test with multiple comparisons. AMPAR/NMDAR ratios in acute slices were tested for normal distribution, and statistical significance was assessed using one-way or two-way ANOVA with Bonferroni post tests. All data are presented as mean \pm SEM, which is shown as error bars in the graphs. For mEPSCs, statistical significance between distributions was calculated by the Kolmogorov-Smirnov test.

Mass spectrometry (MS). For the MS analysis, the bands corresponding to the immunoprecipitated PSD-93 were cut from precast NuPAGE $4-12 \%$ Bis-Tris gels (Invitrogen) and the proteins were digested in-gel using either trypsin or chymotrypsin (Shevchenko et al., 1996). After cleavage, peptides were extracted and analyzed on an LC-coupled LTQ Orbitrap XL (Thermo Fisher Scientific) mass spectrometer under standard conditions. The MS and MS/MS spectra were searched in the NCBI NR database using the Mascot algorithm (Perkins et al., 1999). The following search parameters were used: taxonomy Mammalia, cleavage sites allowed, oxidized methionine, and carbamyl-cysteine as variable modification.

Antibodies, immunoprecipitation, and Western blots. The following antibodies were used for Western blotting: rabbit GFP antibody (Invitrogen), mouse Mortalin, PSD-93, PSD-95, GluA2, GluN2B antibodies (University of California at Davis/National Institutes of Health NeuroMab), rabbit PSD-93 antibody (gift from Dr. David Bredt), mouse DLGMAGUK/SAP97 antibody (Assay Designs), mouse GAPDH antibody (Millipore Bioscience Research Reagents), goat anti-mouse Alexa-680 (Invitrogen), goat anti-rabbit Alexa-680 (Invitrogen), goat anti-mouse IR800 (LI-COR Biosciences), goat anti-rabbit IR800 (LI-COR Biosciences). Hippocampi of mice from either sex were homogenized in homogenization buffer (320 mm sucrose, $10 \mathrm{~mm}$ HEPES/NaOH, pH 7.4). Cell debris and nuclei were removed by centrifugation for $10 \mathrm{~min}$ at $1000 \times \mathrm{g}$ to obtain the supernatant S1. PSD-93 was immunoprecipitated from the S1 fraction solubilized with $1 \%$ sodium N-lauryl sarcosine by incubation with a mouse PSD-93 antibody, followed by a pull-down with anti-mouse IgG-agarose (Sigma-Aldrich) and released from the beads with SDS sample buffer. Protein concentrations of cell fractions were measured, using the BCA kit (Pierce) and adjusted to 0.5 or $1 \mu \mathrm{g} / \mu \mathrm{l}$ in SDS sample buffer. Total homogenates from neuronal cultures were harvested by lysing the cells in a constant cell number to SDS sample buffer ratio. For Western blots, $\sim 30 \mu \mathrm{g}$ of the protein samples was separated on a $4-12 \%$ Bis-Tris gradient gel (Invitrogen), transferred onto nitrocellulose, and incubated with the indicated antibodies. After incubation with secondary antibodies, the signals were detected and quantified with an Odyssey Infrared Imaging System (LI-COR Biosciences).

Semiquantitative RT-PCR. Total RNA was extracted from different brain areas of adult mice using Trizol (Invitrogen) reagent. Taking random primers, $0.5 \mu \mathrm{g}$ of total RNA was reverse transcribed according to the manufacturer's protocol (High Capacity cDNA Transcription Kit, Applied Biosystems). For PCR amplification, $1 \mu \mathrm{l}$ of cDNA product was used in a $25 \mu \mathrm{l}$ reaction with primers previously published or specified below (Parker et al., 2004).

Primers for RT-PCR analysis. N-terminal isoform-specific primers are as follows: PSD-93 $\alpha 1$ forward (CTGAGCTCTCACCACTCAGTGCCTTC) and PSD-93 reverse (CGGTGGCCCATAAGGATCAGT); PSD-93 $\alpha 2$ forward (AGCTGCCGCTCGGTCTAGGCTG) and PSD-93 reverse; PSD-93 $\beta$ forward (AAGGCAAATGCCCAGCCCAG) and PSD-93 $\beta$ reverse (TAGA GCCGGCTTCCTTGAG);PSD-93 $\gamma$ forward(GTGAAGAAGCTATGCAAC ATGCGT) and PSD-93 $\gamma$ reverse (CGAGTTGCAGTACTGTGCTGG); PSD-93 $\delta$ forward (GGGAGGAAGCCTTTCTATGCAG) and PSD-93 reverse; and PSD-93e forward (GCCAACTGGATGTGTGTGAGCCG) and
PSD-93 $\varepsilon$ reverse (CACAACAGTCTCCAATATGGGTCGC). For the analysis of the C-terminal splice variants, the following primers were used: E15 (AGAAGGGTCACACTAGATGG), E16 (GTGGAAAGAAAGGAGCGT G), E17a (CCATTCTACAAGAACAAGGAGC), E17a' (ATCACTGGTTTC CTGCTCAC), E17 (ATTAGGTGACGACGGTTATGG), E17' (GAGTCT TTGTTCCATAACCGTC), E17b' (AGCTACTTTCGCTATCGCTG), and E18' (GCCTCGTGACAGGTTCATAG).

\section{Results \\ PSD-93 genomic structure and mRNA expression of the $\mathrm{N}$-terminal isoforms in the mouse brain}

Multiple isoforms can be generated from the DLG-MAGUK genes by alternative promoter usage coding for the $\mathrm{N}$-terminal domains (Brenman et al., 1996; Parker et al., 2004; Schlüter et al., 2006) and additionally by alternative splicing of exons in the linker sequence between the SH3 and GK domain (Lue et al., 1994; McLaughlin et al., 2002; Nikandrova et al., 2010). We analyzed the mouse gene for PSD-93 (dlgh2) and compared the exon-intron structure with the PSD-95 (dlgh4) and SAP97 (dlgh1) genes, two other functionally related DLG-MAGUKs, which share a similar gene structure (Fig. 1A) (Schlüter et al., 2006). The N-terminal domains of PSD-95 and SAP97 with a palmitoylation motif have been termed $\alpha$, whereas the L27 domain containing isoforms have been termed $\beta$ (Chetkovich et al., 2002; Schlüter et al., 2006). For easy comparison, we termed the palmitoylated PSD-93 isoforms $\alpha 1$ and $\alpha 2$, instead of $\alpha$ and $\beta$, and the L27 containing PSD-93 isoform $\beta$ instead of $\zeta$ as originally suggested (Parker et al., 2004). For the $\mathrm{N}$-terminal domains, five exons code for the L27 containing $\beta$-isoform and two distinct exons for the palmitoylated $\alpha 1$ - and $\alpha 2$-isoforms. The $\alpha$ or the $\beta$ exons are spliced on the common exon 2, coding for a highly conserved KYRYQDED motif. 3' of exon 2, the unique $\mathrm{N}$-terminal isoforms $\gamma, \delta$, and $\varepsilon$, are coded by single exons and spliced onto the alternative exons 3 and 4 . The $\gamma$ exon contains two putative start codons, which are contained in transcripts of the gene, as shown by the EST clone AW060584.

Using semiquantitative RT-PCR, we detected the expression of all six N-terminal isoforms in mouse hippocampus (Fig. 1B). The genes of $\beta$ and $\varepsilon$ were expressed homogeneously in hippocampus, cerebellum, cortex, olfactory bulb, and spinal cord. The expression patterns of the two $\alpha$-isoforms overlapped, being highest in hippocampus, cortex, and olfactoric bulb, followed by spinal cord and lowest in cerebellum. The expression levels of $\gamma$ and $\delta$-isoforms were highest in the cerebellum and spinal cord, respectively, and were similar in the other brain regions. The linker between the $\mathrm{SH} 3$ and GK domain is alternatively spliced in SAP97, and this splicing determines the association with the interaction partners and subcellular localization (Rumbaugh et al., 2003). The $\mathrm{I} 3$ insert is required for the interaction with $4.1 \mathrm{~N}$ and AKAP79/150 (Lue et al., 1994; Nikandrova et al., 2010). The PSD-93 linker is coded by exons 16, 17a, 17, 17b, and 18 (Fig. 1A). The coded amino acid sequence of exon 17 a shared $\sim 80 \%$ identity with the amino acid sequence coded by I3 of SAP97. The coded amino acid sequence of exon $17 \mathrm{~b}$ is $90 \%$ identical to the translation of SAP97 I5 (Fig. 1C). Using RT-PCR, we tested the expression pattern of these potentially alternatively spliced exons. Combining forward primers in exons 15 and 16 with reverse primers in exons $17 \mathrm{a}, 17$, and $17 \mathrm{~b}$, we amplified one band for the combination of primers 15 and 16 with 17 a or 17 and two bands for the combination of 15 and 16 with $17 \mathrm{~b}$ (Fig. $1 D, E$ ). The individual bands indicated that the exon $17 \mathrm{a}$ and 17 are mutually exclusively expressed. In the lanes with two bands, the size difference indicated that exon $17 \mathrm{~b}$ was expressed either in combination 


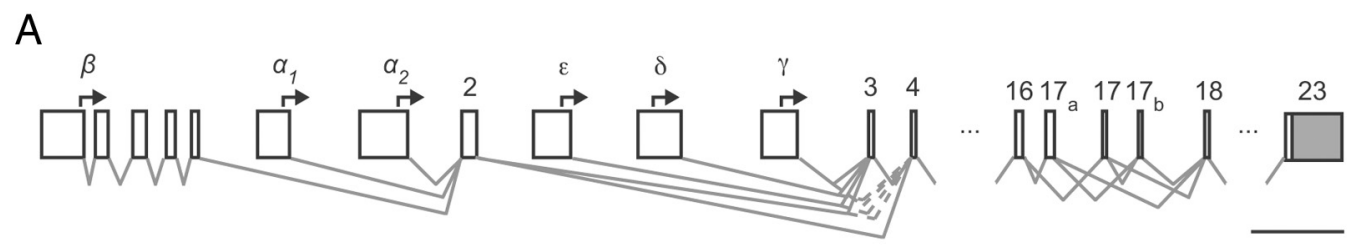

B
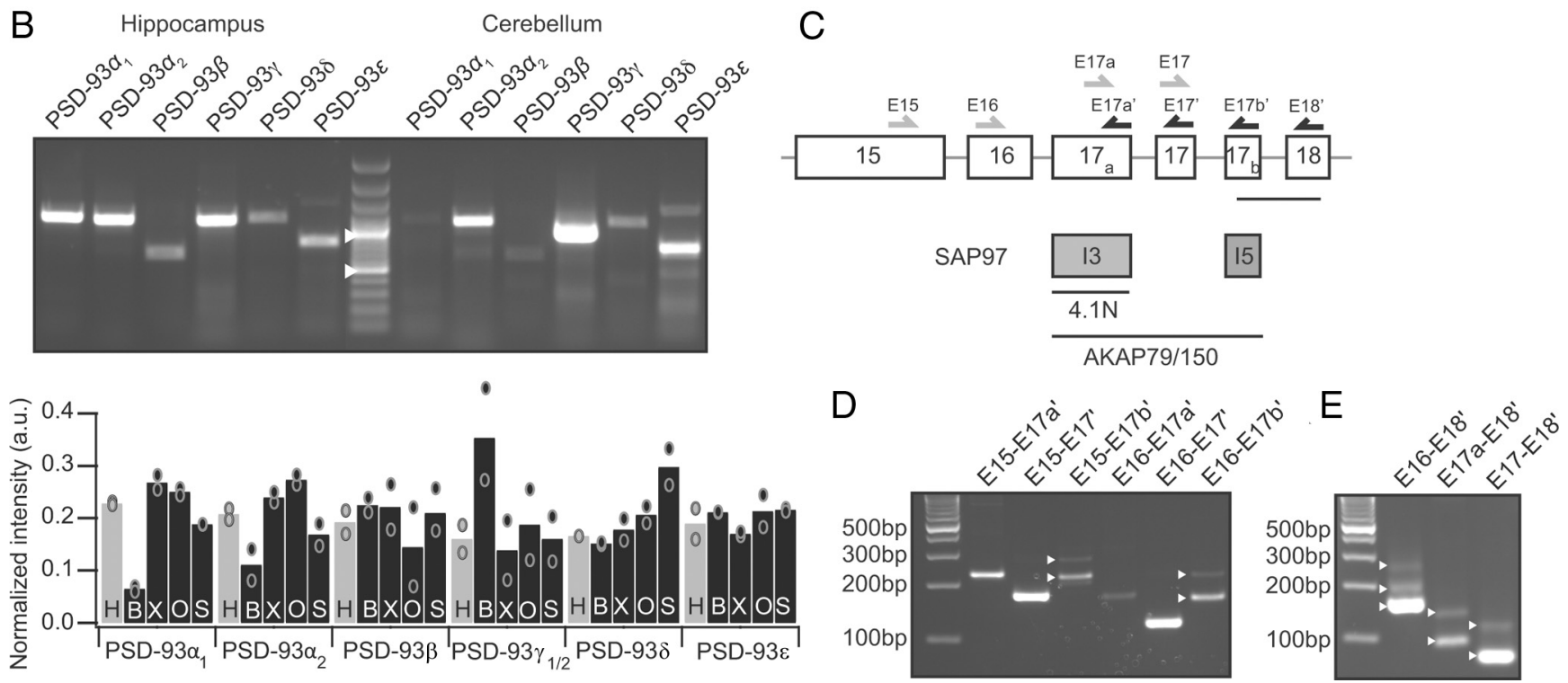

Figure 1. Structure of the PSD-93 gene and mRNA expression in different regions of the CNS. $A$, Structure of the PSD-93 gene with regard to the N-terminal exons and SH-GK linker exons. Exons are drawn to scale. Calibration: $1 \mathrm{~kb}$. Introns not drawn to scale (the high nuclear RNA of PSD-93 $\beta$ spans 1 mega bases). $\boldsymbol{B}$, Comparison of the expression level of the N-terminal is oforms in different CNS regions by RT-PCR (top) and qPCR (bottom), plotted as relative intensities. Bar graph represents mean of the duplicate samples (dots) of one isoform in the different CNS regions. $\mathrm{H}$, Hippocampus; B, cerebellum; X, cortex; 0 , olfactory bulb; S, spinal cord. C, Primer localization for the analysis of the SH3-GK linker characterization and comparison with the corresponding SAP97 exons and identified interaction partners. Calibration: $100 \mathrm{bp} . \boldsymbol{D}, \boldsymbol{E}$, Analytical gels of the RT-PCR analysis of the different splice forms of the SH-GK linker.

with exon 17 a or 17 . The bands with primer 16 were equally shifted upward on the gel compared with the bands with primer 15. The size difference matches the 76 nucleotide (nt) difference in the position of primer 15 and 16 on the transcript, indicating that exon 16 was included in all PSD-93 C-terminal transcripts. To analyze the splicing onto exon 18 , we combined forward primers in exon 16, and the alternative exon $17 \mathrm{a}$ and 17 with a reverse primer in exon 18 (Fig. 1C,E). The primer combination $16 / 18$ yielded three PCR products, in which the smallest matched the calculated size of the exon combination 16-17-18. This observation indicated that each transcript contained either exon 17 or exon 17a. Using the primer combination $17 \mathrm{a} / 18$ and $17 / 18$, we amplified two bands each, which match the calculated size of the exon combinations $17 \mathrm{a}-18$ of $94 \mathrm{nt}, 17 \mathrm{a}-17 \mathrm{~b}-18$ of $136 \mathrm{nt}, 17-18$ of $80 \mathrm{nt}$, and $17-17 \mathrm{~b}-18$ of $122 \mathrm{nt}$. Thus, the exons $17 \mathrm{a}$ and 17 are alternatively spliced and exon 17b is similar to exon I5 of SAP97 a cassette exon, which can be either spliced onto the exons 17 or 17a or excluded from the transcript. For the subsequent functional analysis, we used the $\mathrm{N}$-terminal isoforms in combination with the C-terminal exon combination 16-17-18, which was described in one of the original clones of PSD-93 (Kim et al., 1996).

\section{Protein levels of PSD-93 N-terminal isoforms in the mouse hippocampus}

The RT-PCR experiment suggested that all N-terminal isoforms of PSD-93 are expressed in the hippocampus. To determine the protein level of these isoforms, we took two independent approaches: the quantitative Western blotting and MS. In the West- ern analysis, we took advantage of the size difference among the isoforms and antibodies that detect different subsets of the isoforms. The monoclonal mouse PSD-93 antibody recognized all recombinantly expressed eGFP-tagged isoforms from HEK293 cells with similar strength as judged by quantifying the expression level with double labeling with a GFP antibody (data not shown). Among the recombinantly expressed PSD-93 isoforms, the antibody detecting the $\alpha$ - and $\beta$-isoforms of the DLG-MAGUKs detected only PSD-93 $\alpha 1, \alpha 2$, and $\beta$, whereas a polyclonal rabbit antibody detected all PSD-93 isoforms as control (Fig. 2A). In total mouse hippocampus homogenates, four distinct bands were detected at molecular weights between 100 and $135 \mathrm{kDa}$ (Fig. 2B).

We next determined the identity of these isoforms using a "parallel comparison" strategy. Specifically, in dissociated mouse neuronal cultures, we expressed the untagged isoforms. The endogenous PSD-93 banding pattern of cultures matched the one from hippocampal extracts. To identify specifically the size of the recombinant proteins, the endogenous PSD-93 expression was silenced by the simultaneous expression of an shRNA against mouse PSD-93, resulting in $\sim 90 \%$ knockdown (sh93ms band intensity normalized to control neurons: $9.8 \pm 1.1 \%, n=3$; Fig. $2 B)$. Using the PSD-93 antibody, we compared the size of individual isoforms with the bands of the hippocampal extracts. The $135 \mathrm{kDa}$ band matched the size of the PSD- $93 \beta$ isoform, whereas the strongest band at $110 \mathrm{kDa}$ matched the size of PSD-93 $\alpha 1, \alpha 2$, and $\delta$. Expression of PSD-93 $\gamma$ resulted in two bands, which matched the two lower bands between 100 and $110 \mathrm{kDa}$ in the hippocampal extracts. The size of PSD-93 $\varepsilon$ also matched the low- 
A

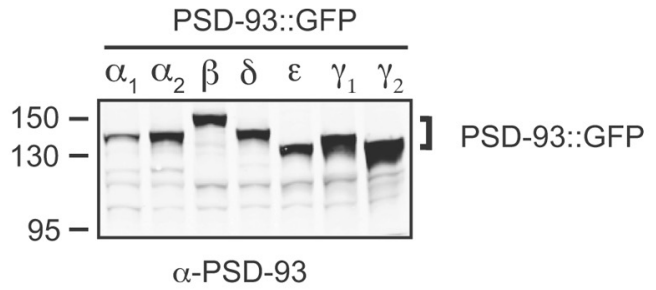

PSD-93::GFP

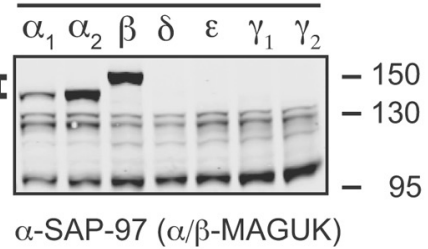

B

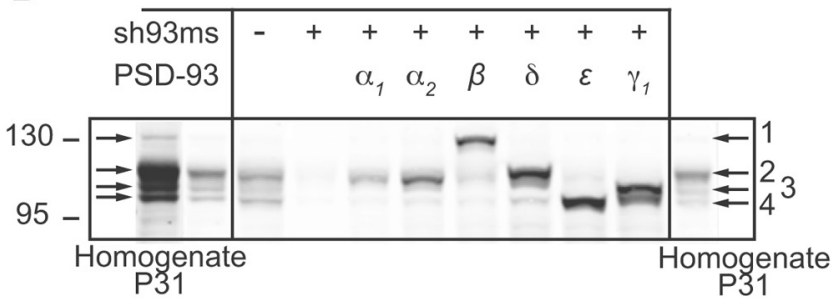

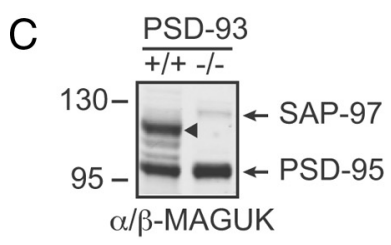

$43-\square$

$\alpha-$ GAPDH
D

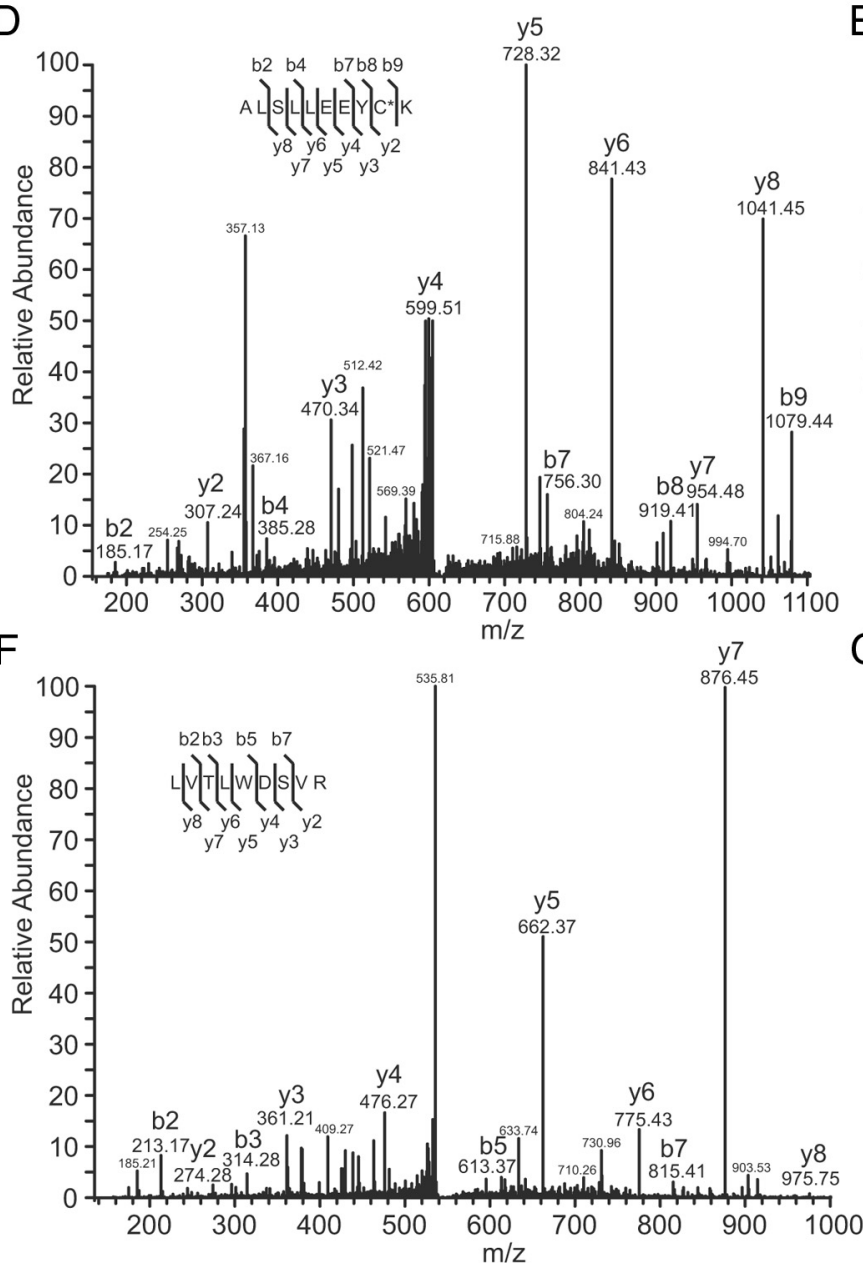

E

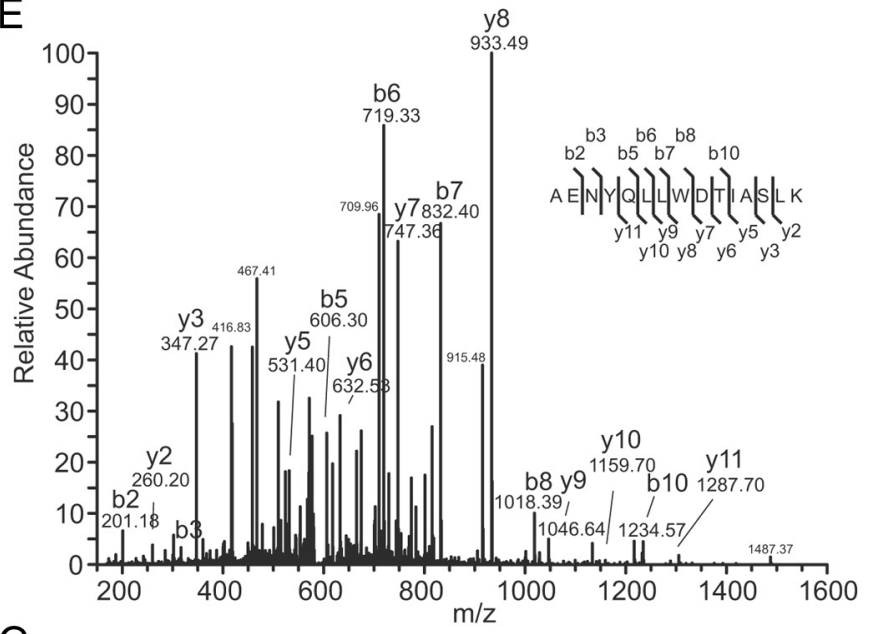

G

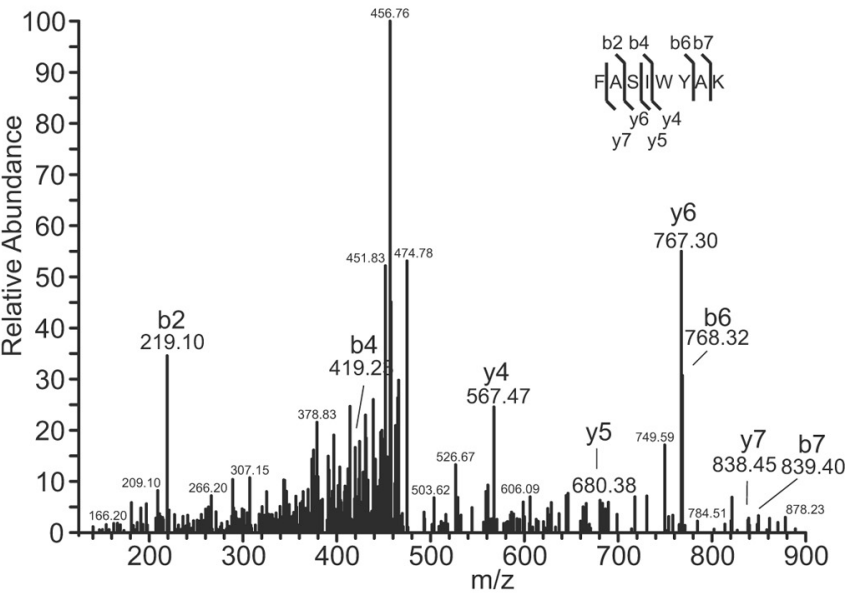

Figure 2. Western blot and mass spectroscopy analysis of the expression of different PSD-93 isoforms in mouse hippocampus. $A$, Test of the mouse PSD-93 antibody (left) and an $\alpha / \beta$ MAGUK (right) to recognize heterologously expressed GFP-tagged PSD-93 isoforms (PSD-93::GFP) in dissociated neuronal cultures. The PSD-93 antibody also recognized endogenous PSD-93 (left blot) and the $\alpha / \beta$ MAGUK antibody endogenous SAP97 ( $\sim 130 \mathrm{kDa}$ ), PSD-93 $\alpha(\sim 110 \mathrm{kDa}$ ), and PSD-95 $\alpha(\sim 95 \mathrm{kDa})$. $\boldsymbol{B}$, Identification (mouse PSD-93 antibody) of the PSD-93 isoforms by size by comparing untagged heterologously expressed PSD-93 isoforms in mouse neuronal cultures with homogenates of mouse hippocampus. Endogenous expression of PSD-93 in culture was knocked down (sh93ms). C, Identification of PSD-93 in mouse hippocampus homogenates of PSD-93 K0 and WT control samples with the $\alpha / \beta$ MAGUK antibody. D-G, MS analysis of the expression of different PSD-93 isoforms in mouse hippocampus reveals isoform-specific peptides after cleavage with endoproteinase trypsin. $\boldsymbol{D}$, MSMS spectrum of isoform $\beta$-specific peptide ALSLLEEYCK. E, MSMS spectrum of isoform $\gamma$-specific peptide AENYQLLWDTIASLK. F, MSMS spectrum of isoform $\delta$-specific peptide LVTLWDSVR. G, MSMS spectrum of isoform $\varepsilon$-specific peptide FASIWYAK. The Mascot scores for the database search are $43,62,62$, and 5 , respectively. The sequences of the peptides are listed within the spectra. Y-type and b-type fragment ions that unambiguously identify the peptides in the database search are listed in the sequence and at the corresponding fragment ions. $C^{*}$, Carbamyl cysteine. 
est band detected in hippocampal extracts. Using the $\alpha / \beta$ MAGUK antibody, we found that the bands at $110 \mathrm{kDa}$ and 135 $\mathrm{kDa}$ were present in hippocampal extracts of wild-type (WT) mice but absent in PSD-93 KO mice, consistent with the above analysis that the $135 \mathrm{kDa}$ band was PSD-93 $\beta$ and the $110 \mathrm{kDa}$ band contained PSD-93 $\alpha 1$ and/or $\alpha 2$ (Fig. $2 C$ ). Using densitometric quantification of the bands, we observed that PSD-93 $\beta$ contributed $10 \%$ to the total PSD-93, the band containing PSD$93 \alpha 1, \alpha 2$, and $\delta$ contributed $50 \%$, and the two lower bands contributed $20 \%$ each.

Results from the above Western analysis were informative but not clear-cut; some bands appeared to contain more components (Fig. 2B). In an attempt to resolve the uncertainties, we next used MS analysis. We immunoprecipitated PSD-93 from the hippocampal extracts and subjected the excised bands after tryptic digestion to LC-coupled tandem MS analysis. The in silico tryptic digest generated one unique peptide for PSD-93 $\alpha 1$, two unique peptides for $\alpha 2,12$ unique peptides for $\beta$, three for $\gamma$, nine for $\delta$, and two for $\varepsilon$. Altogether, 9 of the 29 predicted peptides were identified with the MS analysis. Five peptides were specific for the $\beta$ isoform, confirming its expression in the hippocampus (Fig. $2 D$; R.ALSLLEEYCK.K, R.KPEEQLLK.N, K.IEEANHVAQK.W, K.TLLLDSCR.D, K.SSEHASCSGPK.E). Similarly, the detected peptides unique for $\gamma$ and $\delta$ revealed the presence for these isoforms (Fig. 2E; R.AENYQLLWDTIASLK.Q; Fig. 2F; K.LVTLWDSVR.K, R.SAPTLIR.D). Importantly, the $\gamma$-specific peptide contained the amino acid sequence, including the translation beginning from the first start codon, indicating the expression of the long $\gamma 1$ isoform. Thus, we used the long isoform for our further $\gamma$-isoform-related analysis. One of the $\varepsilon$-unique peptides was detected only with a low ion score (5; Fig. 2G; FASIWYAK.K), which did not unambiguously reveal its expression. For the $\alpha$-isoforms, we did not detect any of the unique peptides, even when reanalyzing the MS data by taking into account that the cysteine residues might be palmitoylated. We sequenced one peptide unique for $\alpha 1$ and $\alpha 2$, encompassing amino acid positions K.ASPAPIIVNTDTLDTIPYVNGTEIEYEFEEITLER.G. In total, we detected altogether 5 peptides, which are specific for the two subgroups of PSD-93 $\alpha 1, \alpha 2$ and $\beta$ or $\alpha 1, \alpha 2$, and $\varepsilon$.

In an attempt to broaden the sequence coverage, we generated alternative peptides by chymotrypsin digestion. Compared with the tryptic digest, the isoform coverage was lower with only one of22 unique peptides identified. A subgroup-specific peptide revealed the expression of PSD-93 $\alpha 1, \alpha 2$ (L.KASPAPIIVNTDTLDTIPY.V). Together with the Western results, we concluded that one or both of the $\alpha$ isoforms (the $\beta, \gamma$, and $\delta$ isoform) are expressed in the mouse hippocampus.

Together, results from the Western and MS analysis are consistent with the expressions of mRNAs from the RT-PCR analysis, but the protein levels of $\alpha$ and $\varepsilon$-isoforms are not unambiguously clear. However, given the clear mRNA signal, the detection of at least one $\alpha$-isoform, and the demonstrated prominent role of these isoforms in regulating synaptic transmission (Schnell et al., 2002; Elias et al., 2006; Schlüter et al., 2006), we included them in the detailed functional characterization together with the other isoforms.

\section{Loss of PSD-93 generated an age-dependent reduction in AMPA receptor function}

To test whether endogenous PSD-93 contributes to basal synaptic transmission, we used a loss-of-function approach. We generated three different shRNA sequences (sh93a, sh93b, and sh93c), aiming to knock down all 6 PSD-93 isoforms in rats. Using dissociated rat neuronal cultures, we first verified the effi- ciency of these constructs (Fig. 3A). Seven days after infection, the levels of all PSD-93 isoforms were reduced. The sh93a and sh93b reduced endogenous PSD- 93 by $>70 \%$ in different independent cultures (sh93a: $21.4 \pm 8.6 \%, n=3$; sh93b: $10.6 \pm 1.7 \%, n=3$ ). The sh $93 \mathrm{c}$ was most efficient and reduced endogenous PSD-93 by $\sim 95 \%$ (sh93c: $2.0 \pm 1.0 \%, n=2$ ). The levels of other synaptic proteins, including PSD-95, GluA2, and GluN2B, did not change significantly. The mouse PSD-93-specific shRNA (sh93ms) did not affect PSD-93 isoforms in rat neuronal cultures but was effective in mouse neuronal cultures (Figs. $2 B, 3 A$ ).

We then tested the effect of the shRNAs in organotypic rat slice cultures. Using parallel dual whole-cell patch-clamp recordings, we measured the AMPAR EPSCs at a holding potential of $-60 \mathrm{mV}$ and the NMDAR EPSCs at a holding potential of $40 \mathrm{mV}$ (60 ms after the AMPAR EPSC peak) simultaneously from a transduced fluorescent neuron and an untransduced neighboring control neuron. This approach allows the quantification of the effect of molecular manipulations on basal synaptic transmission (Hayashi et al., 2000; Schlüter et al., 2006). Expression of these shRNAs had no significant effect on basal synaptic transmission; both the AMPAR and NMDAR EPSCs were not affected (sh93a AMPAR, $n=25$; control, $-39.8 \pm 3.4 \mathrm{pA}$ vs infected, $-36.2 \pm 3.5 \mathrm{pA}, p=0.51 ;$ NMDAR, control, $35.5 \pm 3.9 \mathrm{pA}$ vs infected, $30.9 \pm 3.4 \mathrm{pA}, p=0.39 ; n=22$; sh93b AMPAR, $n=9$; control, $-32.3 \pm 3.8 \mathrm{pA}$ vs infected, $-30.7 \pm 5.0 \mathrm{pA}, p=0.73$; NMDAR, $n=8$; control, $33.4 \pm 5.2 \mathrm{pA}$ vs infected, $23.5 \pm 5.2 \mathrm{pA}$, $p=0.25$; sh93c AMPAR, $n=20$; control, $-52.1 \pm 5.2 \mathrm{pA}$ vs infected, $-46.2 \pm 4.0 \mathrm{pA}, p=0.37$; NMDAR, $n=16$; control, $31.0 \pm 3.8 \mathrm{pA}$ vs infected, $31.8 \pm 4.2 \mathrm{pA}, p=0.71 ; \mathrm{Fig}$. $3 B$ ). In the interleaved controls using an shRNA against PSD-95, we observed a 50\% reduction of AMPAR EPSCs (see Fig. 5A), an effect similar to that previously reported (Schlüter et al., 2006). These results were apparently at odds with a previous study, showing a $50 \%$ reduction of AMPAR EPSCs in rat organotypic slice cultures (Elias et al., 2006). In an attempt to resolve this discrepancy, we measured AMPAR/NMDAR EPSC ratios in acute slices from PSD-93 KO and WT mice (McGee et al., 2001). To test whether developmental differences occur in the strength of basal synaptic transmission, we analyzed slices from three different age groups: P13-P17 during hippocampal development, P25-P30 shortly after hippocampal development, and P60-P74 mature hippocampus. The AMPAR/NMDAR EPSC ratio gradually increased during the three time points in WT mice $\left(F_{(2,41)}=18.80, p<\right.$ 0.01 ; P13-P17, $1.31 \pm 0.14$ vs P25-P30, $2.87 \pm 0.28, p<0.05$; P25-P30 vs P60-P74, $4.36 \pm 0.52$, $p<0.05$; Fig. $3 C, D$ ), consistent with the maturation of AMPAR-silent synapses into AMPAR containing ones (Durand et al., 1996). In PSD-93 KO mice, the AMPAR/NMDAR EPSC ratio increased from P13-P17 to P25P30 but then remained on that level $\left(F_{(2,38)}=20.87, p<0.01\right.$; $\mathrm{P} 13-\mathrm{P} 17,1.33 \pm 0.13$ vs $\mathrm{P} 25-\mathrm{P} 30,2.88 \pm 0.24, p<0.01$; P25-P30 vs P60-P74, $2.74 \pm 0.23, p=0.88$; Fig. 3C,D). Consequently, the AMPAR/NMDAR EPSC ratio was larger in WT mice on P60-P74 compared with that of $P S D-93 \mathrm{KO}$ mice, although we did not measure any difference at the time points earlier $\left(F_{(2,80)}=5.22\right.$, $p<0.01$, two-way ANOVA; WT P60-P74 vs KO P60-P74, $p<$ $0.01)$. Thus, the lack of change in AMPAR/NMDAR ratios in young mice was consistent with previous reports showing no difference in basal synaptic transmission in PSD-93 KO mice (Migaud et al., 1998; Elias et al., 2006). The difference in older animals (P60-P74) suggested, that during late development in the hippocampus, the lack of PSD-93 caused impairments in glutamatergic synapses. Apparently, this condition might be phenocopied under some culturing conditions in organotypic slice 
A

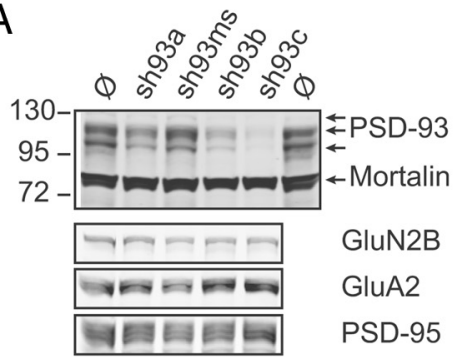

C

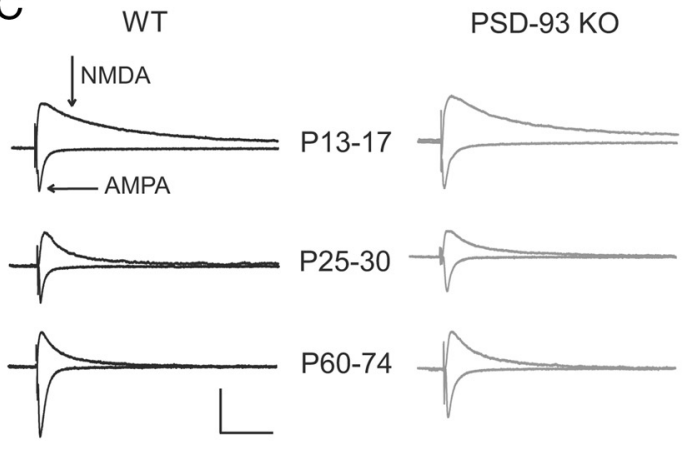

B
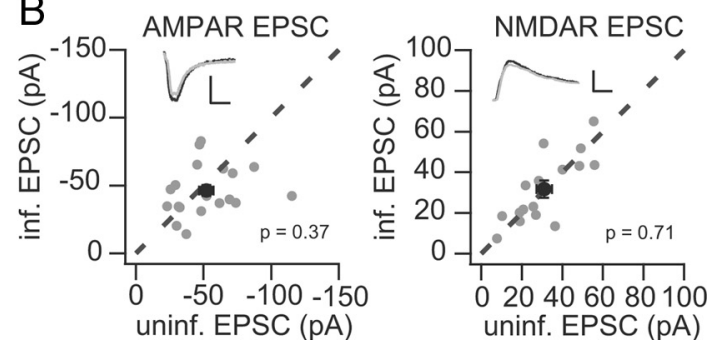

D

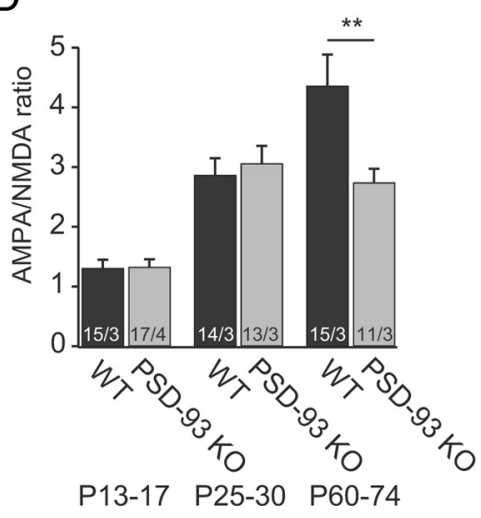

Figure 3. Synaptic development-dependent changes in glutamatergic synaptic transmission after loss of PSD-93. A, Rat dissociated hippocampal neuronal cultures were transduced at DIV 7 with indicated shRNA-expressing lentiviral constructs. Lysates of the neurons after DIV 14 were immunoblotted with antibodies against PSD-93, mortalin as loading control, GluN2B, GluA2, and PSD-95. $B$, Amplitude of AMPAR EPSCS (left) and NMDAR EPSCs (right) of neurons expressing shRNA sh93c was plotted against those of simultaneously recorded uninfected neighboring neurons in rat hippocampal slice cultures. Gray symbols represent single pairs of recordings; black symbols represent mean \pm SEM. $p$ values are calculated by Wilcoxon Signed-Rank test statistic. Insets, Sample traces of control (black) and infected neurons (gray). Calibration: 25 pA, 20 ms. C, Sample traces of evoked glutamatergic synaptic transmission in acute mouse hippocampal slices at different postnatal (P) ages of PSD-93 KO and littermate control animals. Arrows indicate the peak of the AMPAR EPSC of traces recorded at $\mathrm{V}_{\mathrm{h}}=-60 \mathrm{mV}$ and NMDAR EPSC of traces recorded at $\mathrm{V}_{\mathrm{h}}=40 \mathrm{mV}$. Calibration: $100 \mathrm{pA}$ and $100 \mathrm{~ms}$. D, Summary graph of AMPAR/NMDAR ratios plotted against genotype and postnatal ages. Number of cells/animals indicated in foot of the bar. ${ }^{* *} p<0.01$ (two-way ANOVA with Bonferroni post hoc test).

cultures because it was previously reported that knockdown of PSD-93 caused a selective reduction in AMPAR function (Elias et al., 2006). Notably, the lack of effect of the sh93 constructs in our slice cultures mimicked the phenotype in young up to P30 PSD-93 KO mice.

Together, these results suggested that loss of PSD-93 did not affect young synapses in the Schaffer-collateral CA1 pyramidal neuron pathway significantly but was required for proper glutamatergic synaptic transmission in adult synapses.

\section{Role of N-terminal PSD-93 isoforms in regulating AMPA receptor function}

The $\alpha$-isoforms of PSD-93, PSD-95, and SAP97 enhanced AMPAR function when overexpressed in hippocampal organotypic slices (Schnell et al., 2002; Béique and Andrade, 2003; Ehrlich and Malinow, 2004; Nakagawa et al., 2004; Elias et al., 2006; Schlüter et al., 2006). However, the role of other isoforms, which made up to $50 \%$ of the total PSD-93 in the hippocampus (Fig. $2 B, C$ ), is not well understood. To generate a thorough understanding about PSD-93, we examined all PSD-93 isoforms side by side in their regulation of excitatory synaptic transmission.

We first tested the effects of gain of function of the individual PSD-93 isoforms. Using rat organotypic hippocampal slices, we overexpressed the individual isoforms as eGFP-tagged fusion proteins from lentiviral expression vectors (Schlüter et al., 2006). Neither of the two $\alpha$ isoforms enhanced AMPAR function when overexpressed (PSD-93 $\alpha 1, n=14$; control, $-48.6 \pm 4.0 \mathrm{pA}$, infected, $-43.7 \pm 6.2 \mathrm{pA}, p=0.33$; PSD-93 $\alpha 2, n=13$; control, $65.9 \pm 9.5 \mathrm{pA}$; infected, $-58.7 \pm 5.3 \mathrm{pA}, p=0.64$; Fig. $4 A, B, H)$.
This result was seemingly in contradiction to a previous study, in which overexpression of PSD-93 $\alpha 1$ as well as PSD-95 $\alpha$ enhances AMPAR function (Elias et al., 2006). To rule out that our eGFP tag compromised the function of the tagged protein, we expressed PSD-93 $\alpha 2$ in a bicistronic vector separated from eGFP. Overexpression of PSD-93 22 by this strategy did not enhance AMPAR EPSCs either; indeed, it slightly but significantly reduced them $(n=11$, control, $-38.9 \pm 5.1 \mathrm{pA}$; infected, $-25.8 \pm 2.4 \mathrm{pA}$, $p<0.05$; Fig. 4C,H).

We then moved on to other PSD-93 isoforms. Consistent with results from overexpression of PSD-95 $\beta$ and SAP97 $\beta$, overexpression of PSD-93 $\beta$ did not affect AMPAR EPSCs $(n=14$; control, $-44.6 \pm 5.7 \mathrm{pA}$; infected, $-46.4 \pm 4.9 \mathrm{pA} ; p=0.67$; Fig. $4 D, H$ ) (Schnell et al., 2002; Schlüter et al., 2006). Similarly, overexpression of the long $\gamma$-isoform did not affect AMPAR EPSCs $(n=8$, control $-33.4 \pm 2.2 \mathrm{pA}$; infected, $-42.0 \pm 7.1 \mathrm{pA}, p=$ 0.25 ; Fig. $4 E, H)$. On the other hand, overexpression of either PSD-93 $\delta$ or $\varepsilon$ increased the peak amplitude of AMPAR EPSCs (PSD-93 $\delta, n=18$; control, $-37.4 \pm 4.1 \mathrm{pA}$; infected, $-53.5 \pm$ $4.9 \mathrm{pA}, p<0.001$; PSD-93 $\varepsilon, n=11$; control, $-41.6 \pm 6.5 \mathrm{pA}$; infected, $-75.0 \pm 9.6 \mathrm{pA}, p<0.001$; Fig. $4 F-H)$. Because these two isoforms do not contain the $\mathrm{N}$-terminal conserved region, which is important for the $\mathrm{N}$-terminal multimerization of the $\alpha$-DLG-MAGUKs, their mechanism of enhancing AMPAR function is likely to be different from the $\alpha$-isoform-mediated effect (Xu et al., 2008).

Similar to other DLG-MAGUKs, NMDAR function was not affected by overexpression of either of the PSD-93 isoforms (Fig. 4) (Schnell et al., 2002; Elias et al., 2006; Schlüter et al., 2006). 

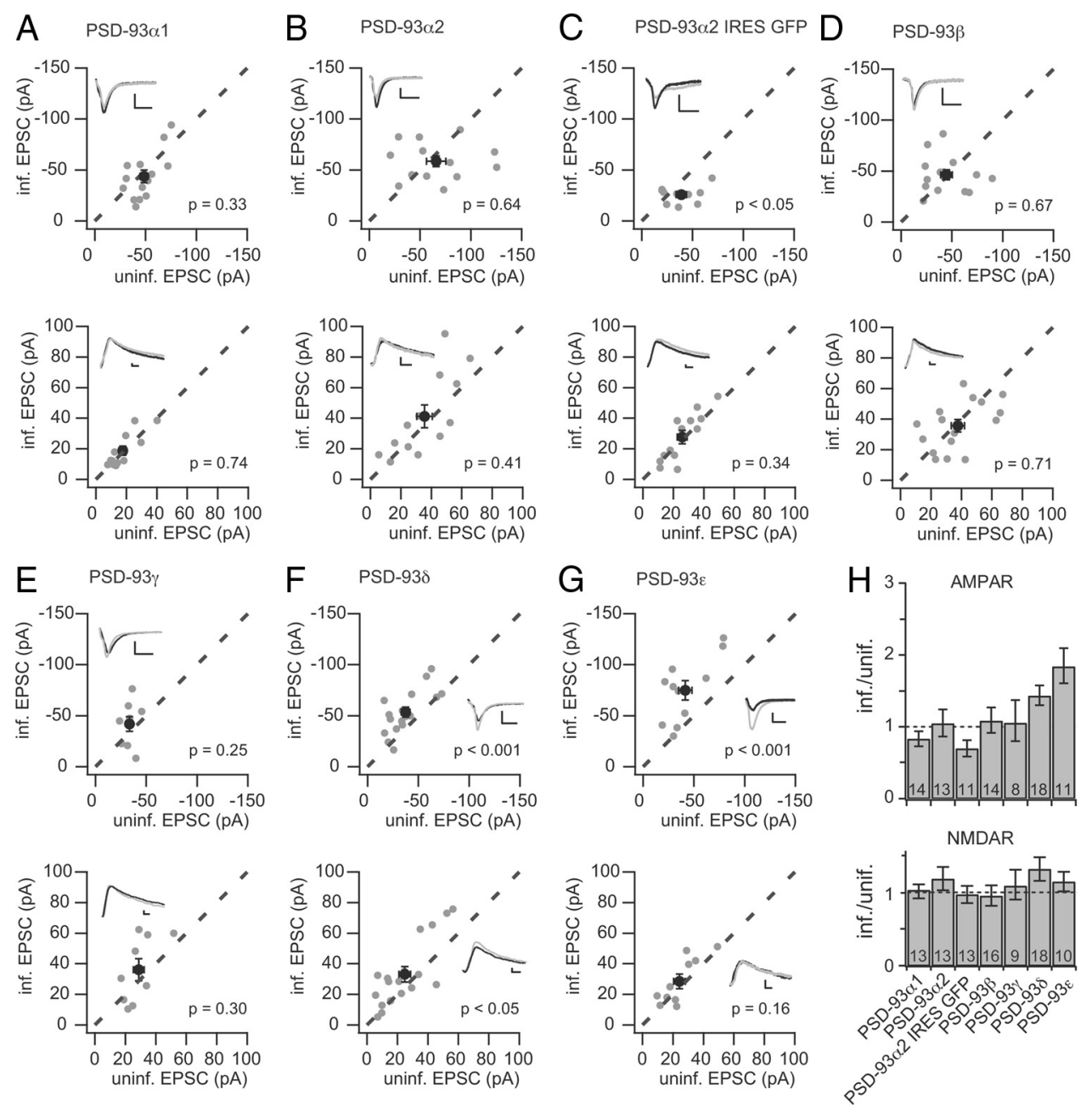

Figure 4. Different effects of PSD-93 isoforms on strength of AMPAREPSCS. Amplitude of AMPAR EPSCs (top) and NMDAR EPSCs (bottom) of neurons expressing eGFP-tagged ( $\boldsymbol{A}$ ) PSD-93 $\alpha 1$, (B) PSD-93 $\alpha 2$, (D) PSD-93 $\beta$, (E) PSD-93 $\gamma$, (F) PSD-93 $\delta$, (G) PSD-93 $\varepsilon$, or ( ( none-tagged PSD-93 $\alpha 2$ with eGFP expressed from another cistron, are plotted against those of simultaneously recorded uninfected neighboring neurons in rat hippocampal slice cultures. $\boldsymbol{H}$, Summary bar graph of EPSC ratio of infected versus uninfected control cell for AMPARs (top) and NMDARs (bottom). Calibration: 100 pA and $100 \mathrm{ms.}$

However, overexpression of PSD-93 $\delta$ caused a significant increase in the amplitude of NMDAR EPSCs (amplitude measured at $60 \mathrm{~ms}$ after the peak, see Materials and Methods: $n=18$; control, $24.8 \pm 3.8$ pA; infected, $33.2 \pm 5.1 \mathrm{pA}, p<0.05$; Fig. 4). To verify this effect on NMDARs, we isolated NMDAR EPSCs by blocking AMPAR EPSCs with $10 \mu \mathrm{M}$ NBQX. With this approach, no significant change was observed in neurons overexpressing PSD-93 $(n=7$; control, $32.3 \pm 3.4 \mathrm{pA}$; infected, $35.5 \pm 1.9 \mathrm{pA}$, $p=0.38$ ). Because prolonged overexpression of PSD-95 can change presynaptic release of glutamate (Futai et al., 2007), which may affect the amplitude of EPSCs as well as the decay kinetics of EPSCs, we tested whether overexpression of PSD-93 $\delta$ affected the paired-pulse ratios (PPRs; interpulse interval, $100 \mathrm{~ms}$ ), which is often altered by changes in presynaptic release. However, overexpression of PSD-93 $\delta$ did not significantly affect the PPR (PPR control, $1.78 \pm 0.12$; infected, $1.76 \pm 0.13 ; p=1.0 ; n=5)$. In conclusion, our results suggested that overexpression of the $\delta$ and $\varepsilon$-isoforms, but not other isoforms of PSD-93, enhanced AMPAR function.

\section{Interaction between of PSD-93 and PSD-95}

DLG-MAGUKs can interact with each other when regulating synaptic transmission. For example, the enhancement of AMPAR responses by SAP97 $\beta$ is modulated by PSD-95
(Schlüter et al., 2006). Because PSD-95 and PSD-93 can be coimmunoprecipitated from brain extracts and colocalized in isolated PSDs, we speculated that endogenous PSD-95 might mask the effects of PSD-93 on AMPARs (Sans et al., 2000; DeGiorgis et al., 2006). To test this hypothesis, we overexpressed the PSD-93 isoforms while simultaneously knocking down the expression of endogenous PSD-95 with a lentiviral molecular replacement vector (Schlüter et al., 2006). Consistent with previous findings, knockdown of PSD-95 alone (by sh95) selectively reduced the amplitude of AMPAR EPSCs by $50 \%$ and had no significant effect on NMDAR EPSCs $(n=16$; AMPAR EPSCs control, $-46.7 \pm 6.2 \mathrm{pA}$; infected, $-23.8 \pm$ $2.7 \mathrm{pA}, p<0.01$; NMDAR EPSCs control, $26.2 \pm 4.4 \mathrm{pA}$; infected, $24.0 \pm 2.9 \mathrm{pA}, p=0.54$; Fig. $5 \mathrm{~A}, H$ ) (Nakagawa et al., 2004; Elias et al., 2006; Schlüter et al., 2006). A previous study attributed these effects to an increase in the fraction of AMPAR-silent synapses (Elias et al., 2006). Consistent with this notion, we detected a decrease in the frequency, but not the amplitude, of miniature EPSCs (mEPSCs) in the sh95expressing neurons (mEPSC amplitude: control, $-19.2 \pm 0.4$ $\mathrm{pA}, n=24$; infected, $-19.6 \pm 0.6 \mathrm{pA}, n=19$, KolmogorovSmirnov, $p=1.0$; mEPSC interevent interval $(\Delta t)$ : control, $1.0 \pm 0.1 \mathrm{~s}$; infected: $1.5 \pm 0.2 \mathrm{~s}$, Kolmogorov-Smirnov, $p<$ 0.05; Fig. 6A). 
Similar to SAP97 $\beta$, PSD-95 replacement with the PSD-93 isoforms $\alpha 1, \alpha 2, \beta$, or $\gamma$ rescued AMPAR function to the control cell levels $(\alpha 1, n=8$; AMPAR EPSCs control, $-61.7 \pm 8.3 \mathrm{pA}$; infected, $-50.0 \pm 7.4 \mathrm{pA}, p=0.38 ; \alpha 2, n=10$; AMPAR EPSCs control, $51.1 \pm 7.6 \mathrm{pA}$; infected, $60.1 \pm 6.8 \mathrm{pA}, p=0.28 ; \beta, n=$ 11 ; AMPAR EPSCs control, $-46.7 \pm 5.4$ pA; infected, $-61.8 \pm 14.4 \mathrm{pA}, p=0.52$; $\gamma, n=13$; AMPAR EPSCs control, $-44.7 \pm 5.8 \mathrm{pA} ;$ infected, $-39.4 \pm 5.9$ pA, $p=0.43$; Fig. $5 B-E, H)$. These results suggested that these PSD-93 isoforms can compensate for the loss of PSD-95 function but did not enhance AMPAR function above control level in either the presence or absence of PSD-95. To test whether the rescue was mediated by increasing the fraction of synapses with AMPARs or the number of AMPARs in active synapses, we measured mEPSCs for the PSD-93 $\alpha 2$ replacement. PSD-95-toPSD-93 22 replacement did not rescue the sh95-caused decrease in frequency of mEPSCs and had no influence on the amplitude either (mEPSC amplitude: control, $-19.1 \pm 0.4 \mathrm{pA}, n=22$; infected, $-19.1 \pm 0.6 \mathrm{pA}, n=16$; KolmogorovSmirnov, $p=0.82$; mEPSC $\Delta t$ : control, $0.91 \pm 0.1 \mathrm{~s}$; infected, $1.6 \pm 0.3 \mathrm{~s}$, Kolmogorov-Smirnov, $p<0.01$; Fig. 6C). These results suggested that expression of PSD-93 $\alpha 2$ did not increase the number of synapses with AMPARs. On the other hand, the PSD-95-to-PSD-95 $\alpha$ replacement increased the frequency of mEPSC above the control cell levels with a small increase of the amplitude as well (mEPSC amplitude: control, $-18.8 \pm 0.5 \mathrm{pA}, n=20$; infected, $-21.3 \pm$ $1.2 \mathrm{pA}, n=15$, Kolmogorov-Smirnov, $p=0.13 ; \operatorname{mEPSC} \Delta t$ : control, $1.6 \pm 0.2 \mathrm{~s}$; infected, $0.7 \pm 0.1 \mathrm{~s}$, Kolmogorov-Smirnov, $p<0.01$; Fig. $6 B$ ), indicating primarily an increase of synapses with AMPARs (Stein et al., 2003). When we compared the average amplitudes of the PSD-95-to-PSD-95 $\alpha$ replacement and control neurons, we measured a statistically significant increase (Wilcoxon Mann-Whitney, $p<0.05$ ), consistent with the trend observed with the amplitude distribution comparison. Notably, the lentivirus-mediated PSD-95-to-PSD-95 $\alpha$ replacement results in higher levels of PSD-95 than that in nonmanipulated cells, resulting in the increased responses in evoked transmission (Schlüter et al., 2006).

PSD-95-to-PSD-93 $\delta$ replacement also rescued AMPAR EPSCs to the control cell level $(n=14$; control, $-50.5 \pm 3.9 \mathrm{pA}$; infected, $-60.1 \pm 6.6 \mathrm{pA}, p=0.15$; Fig. $5 F, H)$. Similar to that of PSD-95 $\alpha$, PSD-93 $\delta$-rescued neurons showed an increase in mEPSC frequency, but not amplitude (amplitude: control, $-19.6 \pm 0.5 \mathrm{pA}, n=15$; infected, $-21.7 \pm 1.1 \mathrm{pA}, n=14$, Kolmogorov-Smirnov, $p=0.13$; $\Delta t$ : control, $2.0 \pm 0.2 \mathrm{~s}$; infected, $1.6 \pm 0.3$ s, Kolmogorov-Smirnov, $p<0.05$; Fig. $6 D$ ). These results together suggested that, similar to PSD- $95 \alpha$, PSD- $93 \delta$ primarily increased the number of synapses with AMPARs, but not as effi-
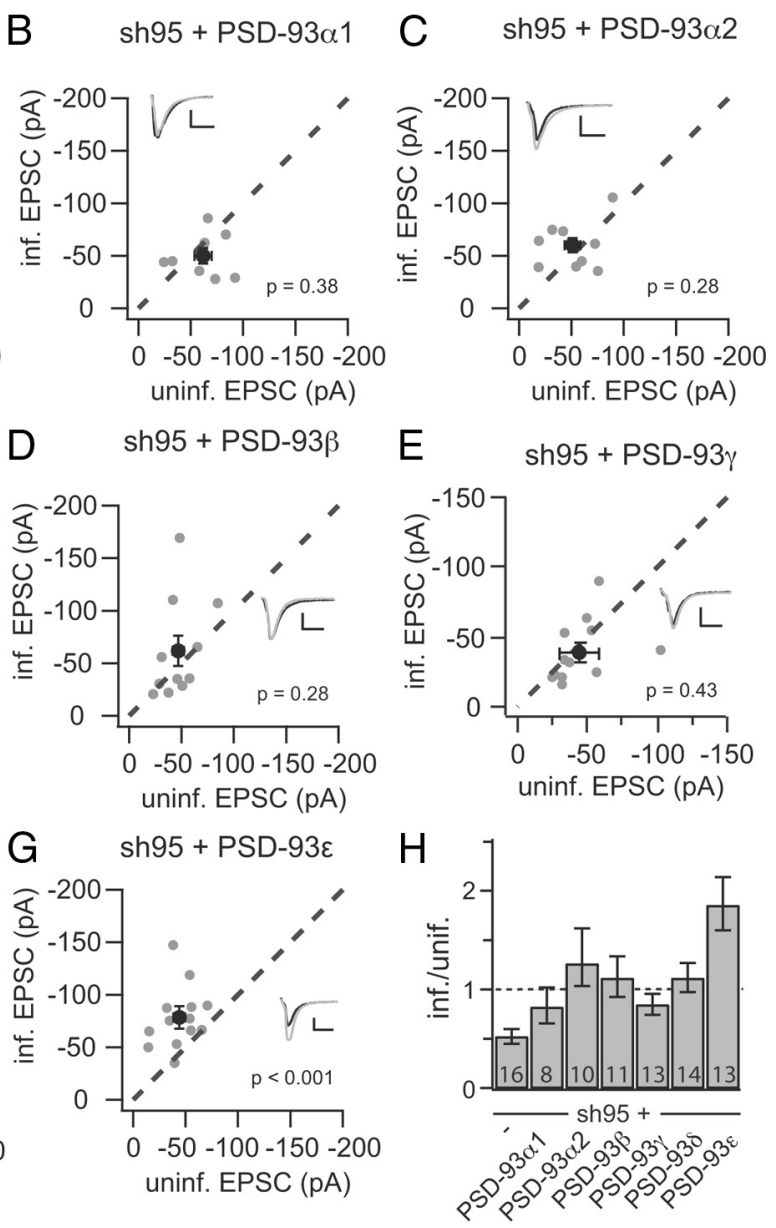

Figure 5. Difference in efficiency of PSD-93 isoforms to rescue AMPAR EPSCs after PSD-95 knockdown. $\boldsymbol{A}-\boldsymbol{G}$, Amplitude of AMPAR EPSCs $(\boldsymbol{A}$, top) and NMDAR EPSCs $(\boldsymbol{A}$, bottom) of neurons expressing $(\boldsymbol{A})$ shRNA against PSD-95, and $(\boldsymbol{B}-\boldsymbol{G})$ eGFP-tagged PSD-95 replacement constructs of (B) PSD-93 $\alpha 1,(\boldsymbol{C})$ PSD-93 $\alpha 2,(\boldsymbol{D})$ PSD-93 $\beta,(\boldsymbol{E})$ PSD-93 $\gamma_{\boldsymbol{1}}(\boldsymbol{F})$ PSD-93 $\delta$, and (G) PSD-93 $\varepsilon$ were plotted against those of simultaneously recorded uninfected neighboring neurons in hippocampal slice cultures. $\boldsymbol{H}$, Summary bar graph of AMPAR EPSC ratio of infected versus uninfected control cell Calibration: 100 pA and $100 \mathrm{~ms}$.

ciently, because the evoked responses of the transduced neurons did not increase above control cell level.

Finally, PSD-95-to-PSD-93 $\varepsilon$ replacement increased the amplitude of AMPAR EPSCs by approximately twofold, similar to the overexpression in naive neurons (with normal level of endogenous PSD-95) ( $n=13$, control, $-43.9 \pm 4.8 \mathrm{pA}$, infected, $-78.5 \pm 8.2$ pA, $p<0.01$; Fig. $5 G, H)$. Furthermore, PSD-93 $\varepsilon$ increased both the frequency and amplitude of mEPSCs (amplitude: control, $-18.5 \pm 0.4 \mathrm{pA}, n=15$; infected, $-20.9 \pm 0.5 \mathrm{pA}$, $n=13$, Kolmogorov-Smirnov, $p<0.05 ; \Delta t$ : control, $1.9 \pm 0.3 \mathrm{~s}$; infected, $1.1 \pm 0.2 \mathrm{~s}$; Kolmogorov-Smirnov, $p<0.05$; Fig. $6 E$ ). This effect of PSD-93 $\varepsilon$ on mEPSCs differed from PSD-95-toPSD-93 $\delta$ replacement. These results together suggested that PSD-93 $\varepsilon$ enhanced AMPARs similar to PSD-95 $\alpha$ despite its different N-terminal structure, lacking the palmitoylation signal and multimerization domain.

\section{Excitatory synaptic activity modulates the effect of PSD-93 $\beta$ and $\delta$ on AMPARs}

The $\beta$-isoforms of PSD-95 and SAP97 function to enhance AMPAR EPSCs in an activity-dependent manner (Schlüter et al., 2006). To increase the excitatory drive on neurons, inhibitory GABAergic transmission was blocked by adding the GABA-A receptor antagonist bicuculline (BIC, $20 \mu \mathrm{M})$ to the culture me- 

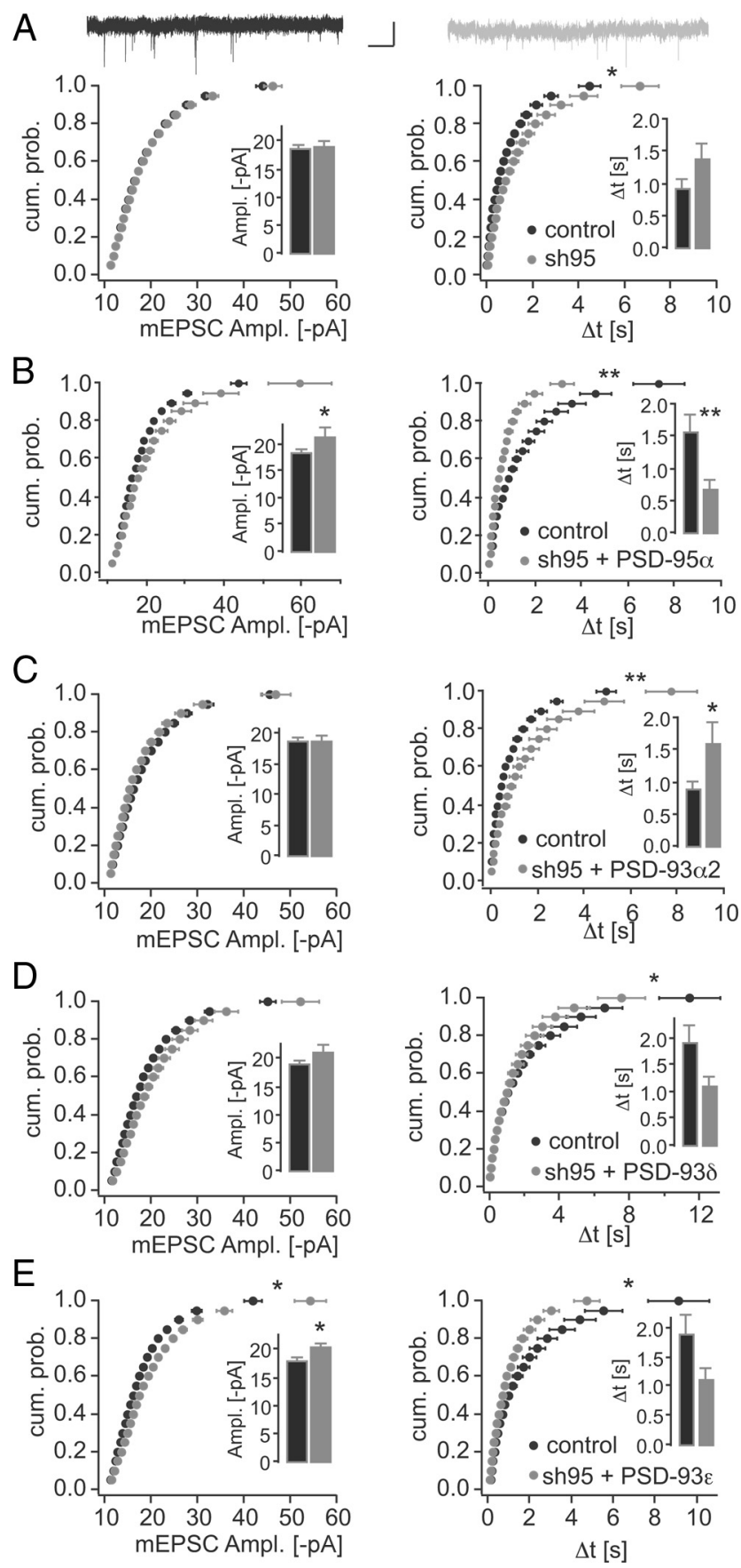

Figure 6. N-terminal isoforms of PSD-93 enhanced AMPAR function by increases in synapses with AMPARs and AMPAR potency. $\boldsymbol{A}$, Top, Cumulative probability plots of mEPSC amplitude (Ampl., left) and interevent interval ( $\Delta t$, right) for knockdown of PSD-95 (black represents sample traces for control; gray represents sample traces for sh95). Calibration: $20 \mathrm{pA}, 1$ S. B, PSD-95 $\alpha$ replacement (RP). C, PSD-93 $\alpha 2$ RP. D, PSD-93 $\delta$ RP. E, PSD-93 $\varepsilon$ RP. Respective controls are also shown. ${ }^{*} p<0.05$, statistical significance between distributions of the molecular manipulation and control neurons (Kolmogorov-Smirnov test). ${ }^{* *} p<0.01$, statistical significance between distributions of the molecular manipulation and control neurons (Kolmogorov-Smirnov test). Insets, Summary graphs for mean mEPSC amplitude (Ampl.) or $\Delta t .{ }^{*} p<0.05$ (Wilcoxon-Mann-Whitney two-sample rank test). ${ }^{* *} p<0.01$ (WilcoxonMann-Whitney two-sample rank test).

dium. Chronic BIC treatment induces synaptic downscaling in dissociated neuronal cultures and it strengthens excitatory synapses in roller tube hippocampal slice cultures (Turrigiano et al., 1998; Abegg et al., 2004). To test which of these mechanisms
A
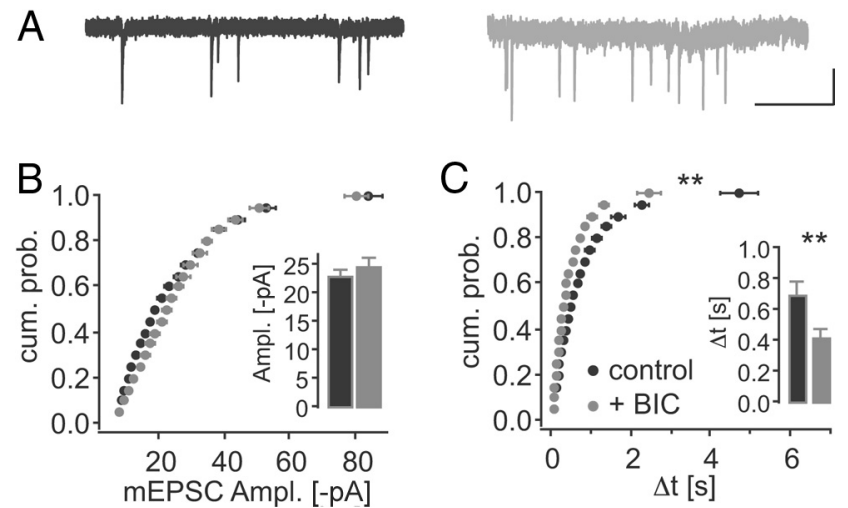

Figure 7. Chronic BIC increased mEPSC frequency, but not amplitude in organotypic slice cultures. $A$, Sample traces of control CA1 pyramidal neurons (black) and after 5-10 d of $20 \mu \mathrm{m}$ BIC-treated cultures. Calibration: $1 \mathrm{~s}, 20 \mathrm{pA}$. Cumulative probability plots of mEPSC amplitude (Ampl., $\boldsymbol{B})$ and interevent interval $(\Delta t, \boldsymbol{C})$ are illustrated. ${ }^{* *} p<0.01$, statistical significance between distributions of the drug-treated and control neurons (Kolmogorov-Smirnov test). Insets, Summary graphs for mean mEPSC amplitude (Ampl.) or $\Delta t .{ }^{* *} p<0.01$ (WilcoxonMann-Whitney two-sample rank test).

predominated in our interface slice culture system, we measured mEPSC frequency and amplitude in chronic BIC-treated cultures. Similar to the roller tube slice cultures, we measured a twofold increase in mEPSC frequency without a change in the mEPSC amplitude (amplitude: control, $-23.3 \pm 1.0 \mathrm{pA}, n=17$; + BIC, $-24.9 \pm 1.3 \mathrm{pA}, n=19$, Wilcoxon Mann-Whitney, $p=$ 0.40 ; $\Delta t$ : control, $0.7 \pm 0.1 \mathrm{~s} ;+$ BIC, $0.4 \pm 0.04 \mathrm{~s}$; Wilcoxon Mann-Whitney, $p<0.01$; Fig. 7). However, the distribution of the mEPSC amplitude was shifted with BIC treatment, such that smaller mEPSCs were overproportionally increased (amplitude: Kolmogorov-Smirnov, $p<0.01 ; \Delta t$ : Kolmogorov-Smirnov, $p<$ 0.01 ; Fig. 7). Thus, in contrast to dissociated neuronal cultures, chronic BIC treatment in organotypic slice cultures primarily caused an increase in excitatory synaptic transmission either by increasing release probability and/or increasing the number of synapses with AMPARs. Importantly, BIC treatment rescues the sh95-mediated decrease in AMPAR EPSCs selectively without affecting NMDAR EPSCs, a result, which precludes a presynaptic mechanism (Schlüter et al., 2006). Hence, we conclude that BIC primarily increased synaptic strength by increasing the number of synapses with AMPARs.

To test whether excitatory synaptic activity also affects PSD93-mediated synaptic regulation, we increased the excitatory drive in slice cultures after viral transduction. PSD-95 replacement with PSD-93 $\alpha 1, \alpha 2$, or $\gamma$ rescued the PSD-95 knockdowninduced decrease in AMPAR EPSCs to the control cell levels $(\alpha 1$ : $n=9$; control, $-52.3 \pm 7.6 \mathrm{pA}$; infected, $-52.6 \pm 9.9 \mathrm{pA}, p=$ $1.00 ; \alpha 2: n=10$; control, $-65.9 \pm 13.8 \mathrm{pA}$; infected: $-58.9 \pm 7.6$ pA, $p=0.90 ; \gamma: n=10$; control, $-36.2 \pm 7.3 \mathrm{pA}$; infected, $-40.5 \pm 5.4 \mathrm{pA}, p=0.49$; Fig. $8 A, B, E)$, similar to the culturing condition without BIC (Fig. $5 B, C, E$ ). In contrast, incubation with BIC enhanced the effect of PSD-95-to-PSD-93 $\beta$ replacement on AMPARs by fourfold ( $n=9$, control, $-27.2 \pm 2.5 \mathrm{pA}$; infected, $-113.9 \pm 16.2 \mathrm{pA}, p<0.01$; Fig. $8 C$ ). We then tested whether the BIC-mediated enhancement was NMDARdependent. AMPAR EPSCs in PSD-95-to-PSD-93 $\beta$ replacement cells were not significantly different compared with control cells when, after BIC treatment, the NMDAR-selective antagonist APV was applied $2 \mathrm{~d}$ before analysis $(n=7$; control, $-57.8 \pm 6.8$ pA; infected, $75.2 \pm 12.2 \mathrm{pA}, p=0.22$; Fig. $8 D$ ). Thus, similar to PSD-95 $\beta$ and SAP97 $\beta$, this BIC-mediated enhancement was 
A

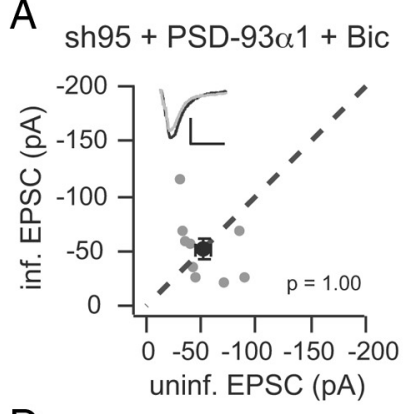

$D_{\text {sh95 }}+$ PSD-93ß + Bic/APV

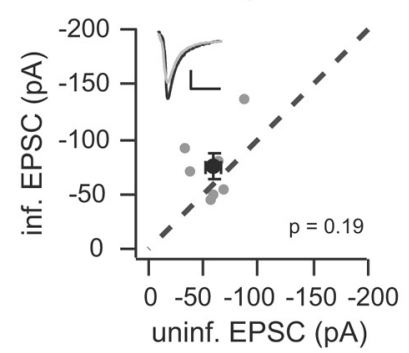

B

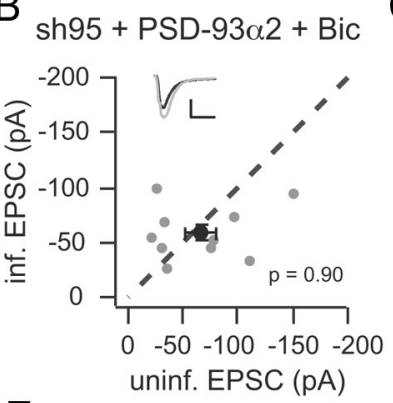

E

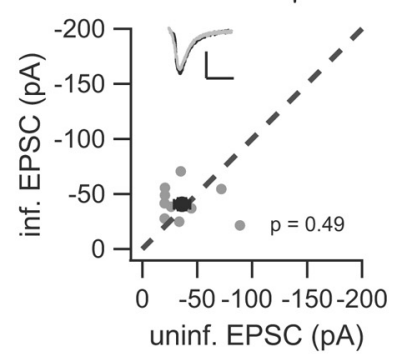

C

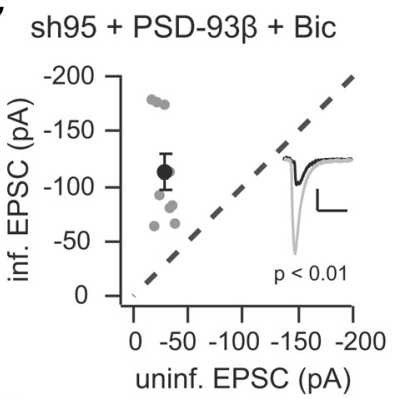

$\mathrm{F}$
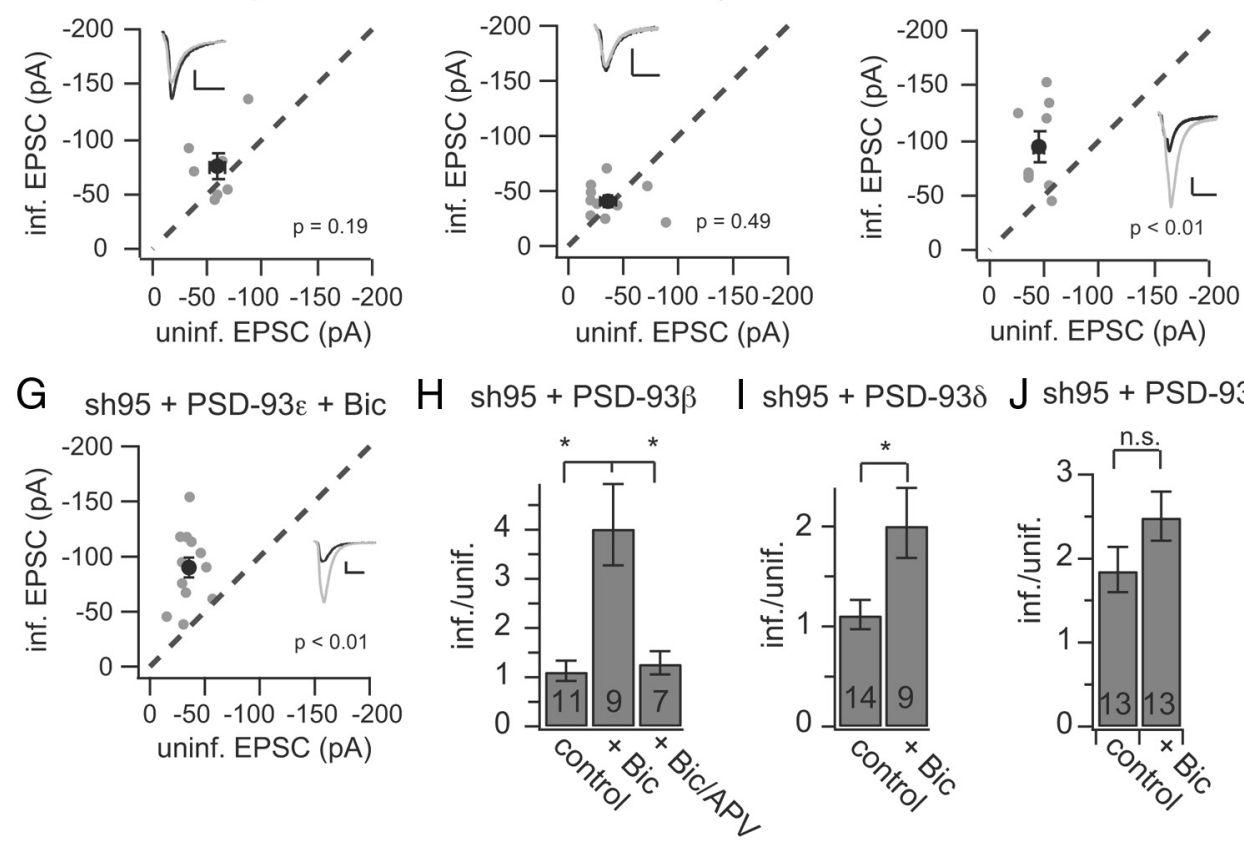

Figure 8. Changes in excitatory synaptic drive modulate function of specific PSD-93 isoforms. By blocking GABAergic synaptic transmission with bicuculline (Bic) in the culture medium, the excitatory synaptic drive was increased. Amplitude of AMPAR EPSC of neurons with eGFP-tagged PSD-95 replacement constructs (A) PSD-93 $\alpha 1$, (B) PSD-93 $\alpha 2$, (C) PSD-93 $\beta$, and (D) PSD-93 $\beta$ with pharmacologically blocked NMDARs (APV), (E) PSD-93 $\gamma,(\boldsymbol{F})$ PSD-938, and (G) PSD-93 $\varepsilon$ were plotted against those of simultaneously recorded uninfected neighboring neurons in hippocampal slice cultures. $\boldsymbol{H}-\boldsymbol{J}$, Comparison of relative AMPAR EPSC changes between control culturing conditions and indicated pharmacological manipulations. I, J, Wilcoxon Mann-Whitney test: ${ }^{*} p<0.05$. n.s., Not significant. $\boldsymbol{H}$, Kruskal-Wallis test with multiple comparisons: ${ }^{*} p<0.05$. Calibration: $100 \mathrm{pA}$ and $100 \mathrm{~ms}$.

NMDAR-dependent and could be fully reversed $\left(\mathrm{H}_{2,24}=13.16\right.$, $p<0.001 ; \mathrm{BIC}, 4.0 \pm \operatorname{SEM}(0.9 ; 0.7)$ vs control, $1.1 \pm 0.2, p<$ 0.05 ; BIC/APV, $1.3 \pm \operatorname{SEM}(0.3 ; 0.2)$ vs control, $p<0.05$; BIC vs BIC/APV,$p>0.05$; Figure $8 H)$. PSD-95-to-PSD-93 $\delta$ replacement also induced enhanced upregulation of AMPAR EPSCs upon incubation of BIC ( $n=9$; control, $-44.3 \pm 3.7 \mathrm{pA}$; infected, $-93.2 \pm 13.1 \mathrm{pA}, p<0.01$; Fig. $8 F, I)$. Incubation of BIC had no significant effect on PSD-93e-mediated upregulation of AMPAR EPSCs; with and without BIC, PSD-95-to-PSD-93 $\varepsilon$ replacement enhanced AMPAR EPSCs by approximately twofold $(n=13$; control, $-35.4 \pm 3.0 \mathrm{pA}$; infected, $-90.0 \pm 9.0 \mathrm{pA}, p<$ 0.01 ; Fig. $8 G, J)$. These results show that, when excitatory synaptic activity was high, PSD-93 $\beta$ was exceedingly more effective in enhancing AMPAR function than other DLG-MAGUK $\beta$-isoforms. Additionally, PSD-93 $\delta$ shared properties of DLG-MAGUK $\alpha$ - and $\beta$-isoforms by enhancing AMPAR EPSCs directly through its synaptic levels and additionally through an activity-dependent mechanism.

\section{Discussion}

DLG-MAGUK scaffolding proteins critically regulate excitatory synaptic transmission. Whereas the synaptic roles of PSD-95,
SAP-97, and SAP102 have been characterized, the role of PSD-93, the most complex paralog of DLG-MAGUKs, remains not well understood. The available results related to PSD-93 are often theoretically inconsistent and sometimes even contradicting. To provide a comprehensive understanding of PSD-93 in excitatory synaptic transmission, we examined all six PSD-93 isoforms in the mouse hippocampus and identified their differential functions. We first demonstrated that the PSD-93 gene shared a similar exon-intron structure as the PSD-95 and SAP97 genes (Fig. $1 A)$; separate promoters and exons downstream of the common exon 2 of the $\alpha$ - and $\beta$-isoforms coded for the additional $\mathrm{N}$-terminal isoforms $\gamma, \delta$, and $\varepsilon$. All six PSD-93 isoforms were expressed in the hippocampus but with different expression levels (Figs. 1, 2). We next demonstrated that these N-terminal isoforms of PSD-93 enhanced AMPAR function by different mechanisms: (1) PSD-93 $\beta$ shared functional properties with the two other DLG-MAGUK $\beta$-isoforms of PSD-95 and SAP97 (Figs. $4,5,8)$; (2) despite their high sequence homology, the two $\alpha$-isoforms of PSD-93 did not exhibit similar enhancing effect on AMPARs as mediated by PSD-95 $\alpha$ and SAP97 $\alpha$ (Figs. 4, 5); (3) PSD-93 $\varepsilon$ was comparably potent as PSD-95 $\alpha$ in enhancing AM- 
PAR function, despite its structural difference (Figs. 4, 5, 6); (4) PSD-93 $\delta$ enhanced AMPAR function when overexpressed, and this enhancement was potentiated by increased excitatory synaptic activity (Figs. 4, 5, 8). These results reveal that different isoforms of PSD-93 expressed in the hippocampus allow for specific and selective modes to regulate synaptic transmission and plasticity and further contributing to the evolutionary broadening of the signaling scaffolds to regulate more complex behaviors (Nithianantharajah et al., 2013).

\section{Abundance of PSD-93 isoforms in the hippocampus}

Using a combination of RT-PCR, Western blotting, and MS, we determined the abundance of all six PSD-93 N-terminal isoforms in the mouse hippocampus. The N-terminal domain of PSD-93 derived from different transcription start sites. Our results show that the transcripts of all six $\mathrm{N}$-terminal isoforms were expressed in the hippocampus. With the combination of isoform groupspecific antibodies, the molecular size, and the fingerprint in MS, we identified unambiguously the expression of PSD-93 $\beta, \delta$, and $\gamma$ in the hippocampus. In addition, both transcripts of the two $\alpha$-isoforms are expressed. On the protein level, however, results are not unambiguous. The corresponding band amounted to $50 \%$ of the total PSD-93 protein; thus, the $\alpha$-isoforms are the most abundant of the PSD-93 isoforms (Fig. 2). The presence of PSD-93 $\varepsilon$ could be derived from the pattern of Western blot bands, although intrinsic uncertainty may be involved in this pattern-based analysis (Fig. 2). The abundance of the other isoforms was estimated to range between $5 \%$ and $20 \%$ based on quantitative Western blots. The relative abundance of these isoforms appeared to differ between regions of the CNS (e.g., the relative abundance of the $\delta$-isoform is low in hippocampus but high in spinal cord) (Leyland and Dart, 2004). These differences in relative abundance may contribute to the functional diversity of synapses in different brain regions and potentially during different developmental stages.

\section{Functional differences of the PSD-93 isoforms}

To test for functional differences among of the PSD-93 $\mathrm{N}$-terminal isoforms, we overexpressed them in organotypic hippocampal slice cultures and measured their gain of function on AMPARs. Both PSD-93 $\delta$ and $\varepsilon$ enhanced AMPAR function. This result adds new isoforms in the DLG-MAGUK subfamily that may upregulate AMPARs during synaptic plasticity. Importantly, the mechanisms underlying these isoform-mediated AMPAR enhancements are different (Figs. 4, 5, 6, 7, 8), and these differential mechanisms allow for specialized modes of synaptic potentiation under different conditions or different brain regions. Specifically, PSD-93 $\varepsilon$-mediated enhancement of AMPARs exhibited similar magnitude when overexpressed in either the presence or absence of endogenous PSD-95 and thus was independent of endogenous PSD-95 (Figs. 4, 5). This enhancement is mediated both by increased numbers of synapses with AMPARs and increase in AMPAR potency, measured as changes in mEPSC frequency and amplitude, respectively (Fig. 6). On the other hand, expression of PSD-95 $\alpha$ or SAP97 $\alpha$ also enhances synaptic responses (Schlüter et al., 2006), but at least for PSD-95 $\alpha$ the enhancement is primarily achieved by delivering new AMPARs to silent synapses (Fig. 6) (Stein et al., 2003). It is also worth noting that the increase in mEPSC frequency in PSD-93-expressed cells is not likely mediated by presynaptic changes because all our manipulations were specific for the postsynaptic site. Rather, as shown previously, upregulating PSD-95 increases the frequency of mEPSC, a process that is mediated by increasing the number of synapses with
AMPARs, potentially via unsilencing of silent synapses (Stein et al., 2003; Elias et al., 2006). When the molecular manipulations last longer, changes in presynaptic release probability are induced by PSD-95 overexpression (Futai et al., 2007). Thus, the increase in $\mathrm{mEPSC}$ frequency may partly be mediated by presynaptic mechanisms. Notably, PSD- $95 \alpha$-mediated enhancement requires N-terminal multimerization, whereas PSD-93e lacks the N-terminal multimerization motif (Parker et al., 2004; Xu et al., 2008). Together, these results suggest a unique role of PSD-93e, as a monomer, in enhancing AMPAR function.

PSD-93 $\beta$ and $\gamma$ did not enhance AMPAR function when overexpressed in neurons with normal expression of PSD-95, but they rescued AMPAR function to the control cell levels when endogenous PSD-95 was knocked down. This function is similar to PSD-95 $\beta$ and SAP97 $\beta$ (Schlüter et al., 2006). In contrast to the $\gamma$-isoform of PSD-93, expression of the $\beta$-isoforms enhanced AMPAR function-dependent on excitatory synaptic activity. This function of PSD-93 $\beta$, although often masked by endogenous PSD-95, may play critical roles under certain conditions. For example, in the developing sensory cortex, immature synapses lack PSD-95 (Yoshii et al., 2003). After eye opening and the start of sensory input, PSD-95 is recruited to these synapses. Thus, there is a time window during which the $\beta$-isoforms actively regulate AMPARs. Given that PSD-95-lacking neurons often possess a high level of silent synapses (Béique et al., 2006), by delivering/stabilizing AMPARs, these $\beta$-isoforms may also function to increase the number of synapses with AMPARs, thus fully activating certain neural circuits (Fig. 8).

PSD-938-mediated AMPAR enhancement required endogenous PSD-95; when PSD-95 was absent, expression of PSD-93 $\delta$ rescued AMPAR-mediated synaptic transmission only to the control cell levels. The AMPAR enhancement mediated by PSD$93 \delta$ was achieved primarily by increasing the number of synapses with AMPARs (Fig. 6). For PSD-938, the enhancement was dependent on excitatory synaptic activity in the slice culture, similar to the $\beta$-isoforms (Fig. 8). Thus, the primary physiological function of PSD-93 $\beta$ and $\delta$ is to regulate synaptic transmission in an activity-dependent manner. This notion is partially supported by the observation that in animals in which all PSD-93 isoforms are knocked out, LTP induction is reduced in hippocampal slices (Carlisle et al., 2008). Given that expression of PSD-93 $\alpha 1$ and $\alpha 2$ did not change AMPAR function (Fig. 4), the reduced LTP may be attributable to other isoforms, including $\beta$ and $\delta$.

Overexpression of PSD-93 $\alpha 1$ and $\alpha 2$ did not enhance AMPAR function. This finding was unexpected, as the $\alpha$-isoforms of the DLG-MAGUKs share a high degree of sequence identity and expression of other DLG-MAGUKs with similar $\mathrm{N}$ terminus does enhance AMPAR function (Schnell et al., 2002; Béïque and Andrade, 2003; Ehrlich and Malinow, 2004; Nakagawa et al., 2004; Schlüter et al., 2006). Upon the PSD-95-to-PSD-93 $\alpha 2$ replacement, the number of synapses with AMPARs (unsilent synapses) was significantly reduced as a consequence of the PSD-95 knockdown (Fig. 6). It remains to be addressed how PSD-93 $\alpha 2$ in this replacement experiment could still rescue AMPAR EPSCs to control cell levels. Nonetheless, the observed minimal effect of the PSD-93 $\alpha$ s on AMPARs is consistent with our other findings. For example, when all PSD-93 isoforms were knocked down, we did not detect any changes in AMPAR function in young synapses (slice culture and acute slice up to P30), whereas knockdown of PSD-95 resulted in a 50\% reduction of AMPAR EPSCs (Figs. 3, 5) (Nakagawa et al., 2004; Elias et al., 2006; Schlüter et al., 2006). Given the lower abundance of all PSD-93 isoforms compared with PSD-95 and particularly the AMPAR-regulating isoforms 
(e.g., PSD-93 $\delta$ and $\varepsilon$ ), a minimal effect on AMPARs was expected upon PSD-93 knockdown (Peng et al., 2004; Cheng et al., 2006). Accordingly, there is no change in AMPAR-mediated synaptic transmission in young PSD-93 KO mice (Elias et al., 2006; Carlisle et al., 2008). In contrast, upon PSD-95 KO or knockdown, AMPAR-mediated synaptic transmission is reduced (Fig. 5) (Nakagawa et al., 2004; Béïque et al., 2006; Elias et al., 2006; Schlüter et al., 2006; Carlisle et al., 2008). Although these results consistently suggest a lack of basal regulation of AMPARs in the young hippocampus by PSD-93 as discussed above, discrepant results are observed. It has been shown in rat hippocampal slice cultures that overexpression of PSD-93 $\alpha 1$ enhances AMPAR function, and knockdown of PSD-93 reduces AMPAR function by $\sim 50 \%$ (Elias et al., 2006), suggesting that PSD-93 $\alpha 1$ may become more "active" under certain experimental conditions. Our results in P60-P74 PSD-93 KO mice show that the AMPA/NMDAR ratio was decreased compared with that of control mice (Fig. 3). Thus, at different developmental synaptic states, PSD-93 may become essential to maintain the synaptic strength.

In conclusion, our results demonstrate differential effects of different PSD-93 isoforms on AMPAR function. These results provide a comprehensive understanding of PSD-93 in regulating synaptic transmission, differentiate the functional difference among DLG-MAGUKs, such as PSD-93 versus PSD95, and help establish a conceptual basis for exploring the roles of other DLGMAGUKs in regulating excitatory synaptic transmission and plasticity.

\section{References}

Abegg MH, Savic N, Ehrengruber MU, McKinney RA, Gähwiler BH (2004) Epileptiform activity in rat hippocampus strengthens excitatory synapses. J Physiol 554:439-448. CrossRef Medline

Béïque JC, Andrade R (2003) PSD-95 regulates synaptic transmission and plasticity in rat cerebral cortex. J Physiol 546:859-867. CrossRef Medline

Béique JC, Lin DT, Kang MG, Aizawa H, Takamiya K, Huganir RL (2006) Synapse-specific regulation of AMPA receptor function by PSD-95. Proc Natl Acad Sci U S A 103:19535-19540. CrossRef Medline

Brenman JE, Christopherson KS, Craven SE, McGee AW, Bredt DS (1996) Cloning and characterization of postsynaptic density 93 , a nitric oxide synthase interacting protein. J Neurosci 16:7407-7415. Medline

Carlisle HJ, Fink AE, Grant SG, O’Dell TJ (2008) Opposing effects of PSD-93 and PSD-95 on long-term potentiation and spike timingdependent plasticity. J Physiol 586:5885-5900. CrossRef Medline

Cheng D, Hoogenraad CC, Rush J, Ramm E, Schlager MA, Duong DM, Xu P, Wijayawardana SR, Hanfelt J, Nakagawa T, Sheng M, Peng J (2006) Relative and absolute quantification of postsynaptic density proteome isolated from rat forebrain and cerebellum. Mol Cell Proteomics 5:1158-1170. CrossRef Medline

Chetkovich DM, Bunn RC, Kuo SH, Kawasaki Y, Kohwi M, Bredt DS (2002) Postsynaptic targeting of alternative postsynaptic density- 95 isoforms by distinct mechanisms. J Neurosci 22:6415-6425. Medline

Cho KO, Hunt CA, Kennedy MB (1992) The rat brain postsynaptic density fraction contains a homolog of the Drosophila discs-large tumor suppressor protein. Neuron 9:929-942. CrossRef Medline

Craven SE, Bredt DS (1998) PDZ proteins organize synaptic signaling pathways. Cell 93:495-498. CrossRef Medline

DeGiorgis JA, Galbraith JA, Dosemeci A, Chen X, Reese TS (2006) Distribution of the scaffolding proteins PSD-95, PSD-93, and SAP97 in isolated PSDs. Brain Cell Biol 35:239-250. CrossRef Medline

Durand GM, Kovalchuk Y, Konnerth A (1996) Long-term potentiation and functional synapse induction in developing hippocampus. Nature 381: 71-75. CrossRef Medline

Ehrlich I, Malinow R (2004) Postsynaptic density 95 controls AMPA receptor incorporation during long-term potentiation and experience-driven synaptic plasticity. J Neurosci 24:916-927. CrossRef Medline

Elias GM, Funke L, Stein V, Grant SG, Bredt DS, Nicoll RA (2006) Synapsespecific and developmentally regulated targeting of AMPA receptors by a family of MAGUK scaffolding proteins. Neuron 52:307-320. CrossRef Medline

Futai K, Kim MJ, Hashikawa T, Scheiffele P, Sheng M, Hayashi Y (2007) Retrograde modulation of presynaptic release probability through signaling mediated by PSD-95-neuroligin. Nat Neurosci 10:186-195. CrossRef Medline

Hayashi Y, Shi SH, Esteban JA, Piccini A, Poncer JC, Malinow R (2000) Driving AMPA receptors into synapses by LTP and CaMKII: requirement for GluR1 and PDZ domain interaction. Science 287:2262-2267. CrossRef Medline

Huettner JE, Baughman RW (1986) Primary culture of identified neurons from the visual cortex of postnatal rats. J Neurosci 6:3044-3060. Medline

Kerchner GA, Nicoll RA (2008) Silent synapses and the emergence of a postsynaptic mechanism for LTP. Nat Rev Neurosci 9:813-825. CrossRef Medline

Kim E, Cho KO, Rothschild A, Sheng M (1996) Heteromultimerization and NMDA receptor-clustering activity of Chapsyn-110, a member of the PSD-95 family of proteins. Neuron 17:103-113. CrossRef Medline

Kistner U, Wenzel BM, Veh RW, Cases-Langhoff C, Garner AM, Appeltauer U, Voss B, Gundelfinger ED, Garner CC (1993) SAP90, a rat presynaptic protein related to the product of the Drosophila tumor suppressor gene dlg-A. J Biol Chem 268:4580-4583. Medline

Leyland ML, Dart C (2004) An alternatively spliced isoform of PSD-93/ chapsyn 110 binds to the inwardly rectifying potassium channel, Kir2.1. J Biol Chem 279:43427-43436. CrossRef Medline

Lois C, Hong EJ, Pease S, Brown EJ, Baltimore D (2002) Germline transmission and tissue-specific expression of transgenes delivered by lentiviral vectors. Science 295:868-872. CrossRef Medline

Lue RA, Marfatia SM, Branton D, Chishti AH (1994) Cloning and characterization of hdlg: the human homologue of the Drosophila discs large tumor suppressor binds to protein 4.1. Proc Natl Acad Sci U S A 91:98189822. CrossRef Medline

Malinow R, Malenka RC (2002) AMPA receptor trafficking and synaptic plasticity. Annu Rev Neurosci 25:103-126. CrossRef Medline

McGee AW, Topinka JR, Hashimoto K, Petralia RS, Kakizawa S, AguileraMoreno A, Wenthold RJ, Kano M, Bredt DS, Kauer F (2001) PSD-93 knock-out mice reveal that neuronal MAGUKs are not required for development or function of parallel fiber synapses in cerebellum. J Neurosci 21:3085-3091. Medline

McLaughlin M, Hale R, Ellston D, Gaudet S, Lue RA, Viel A (2002) The distribution and function of alternatively spliced insertions in $\mathrm{hDlg}$. J Biol Chem 277:6406-6412. CrossRef Medline

Migaud M, Charlesworth P, Dempster M, Webster LC, Watabe AM, Makhinson M, He Y, Ramsay MF, Morris RG, Morrison JH, O’Dell TJ, Grant SG (1998) Enhanced long-term potentiation and impaired learning in mice with mutant postsynaptic density-95 protein. Nature 396:433-439. CrossRef Medline

Müller BM, Kistner U, Veh RW, Cases-Langhoff C, Becker B, Gundelfinger ED, Garner CC (1995) Molecular characterization and spatial distribution of SAP97, a novel presynaptic protein homologous to SAP90 and the Drosophila discs-large tumor suppressor protein. J Neurosci 15:23542366. Medline

Müller BM, Kistner U, Kindler S, Chung WJ, Kuhlendahl S, Fenster SD, Lau LF, Veh RW, Huganir RL, Gundelfinger ED, Garner CC (1996) SAP102, a novel postsynaptic protein that interacts with NMDA receptor complexes in vivo. Neuron 17:255-265. CrossRef Medline

Nakagawa T, Futai K, Lashuel HA, Lo I, Okamoto K, Walz T, Hayashi Y, Sheng M (2004) Quaternary structure, protein dynamics, and synaptic function of SAP97 controlled by L27 domain interactions. Neuron 44: 453-467. CrossRef Medline

Nikandrova YA, Jiao Y, Baucum AJ, Tavalin SJ, Colbran RJ (2010) $\mathrm{Ca}^{2+} /$ calmodulin-dependent protein kinase II binds to and phosphorylates a specific SAP97 splice variant to disrupt association with AKAP79/150 and modulate alpha-amino-3-hydroxy-5-methyl-4-isoxazolepropionic acidtype glutamate receptor (AMPAR) activity. J Biol Chem 285:923-934. CrossRef Medline

Nithianantharajah J, Komiyama NH, McKechanie A, Johnstone M, Blackwood DH, St Clair D, Emes RD, van de Lagemaat LN, Saksida LM, Bussey TJ, Grant SG (2013) Synaptic scaffold evolution generated components of vertebrate cognitive complexity. Nat Neurosci 16:16-24. CrossRef Medline

Ogawa Y, Horresh I, Trimmer JS, Bredt DS, Peles E, Rasband MN (2008) 
Postsynaptic density-93 clusters Kv1 channels at axon initial segments independently of Caspr2. J Neurosci 28:5731-5739. CrossRef Medline

Parker MJ, Zhao S, Bredt DS, Sanes JR, Feng G (2004) PSD93 regulates synaptic stability at neuronal cholinergic synapses. J Neurosci 24:378388. CrossRef Medline

Peng J, Kim MJ, Cheng D, Duong DM, Gygi SP, Sheng M (2004) Semiquantitative proteomic analysis of rat forebrain postsynaptic density fractions by mass spectrometry. J Biol Chem 279:21003-21011. CrossRef Medline

Perkins DN, Pappin DJ, Creasy DM, Cottrell JS (1999) Probability-based protein identification by searching sequence databases using mass spectrometry data. Electrophoresis 20:3551-3567. CrossRef Medline

Roche KW, Ly CD, Petralia RS, Wang YX, McGee AW, Bredt DS, Wenthold RJ (1999) Postsynaptic density-93 interacts with the $\delta 2$ glutamate receptor subunit at parallel fiber synapses. J Neurosci 19:3926-3934. Medline

Rumbaugh G, Sia GM, Garner CC, Huganir RL (2003) Synapse-associated protein-97 isoform-specific regulation of surface AMPA receptors and synaptic function in cultured neurons. J Neurosci 23:4567-4576. Medline

Ryan TJ, Grant SG (2009) The origin and evolution of synapses. Nat Rev Neurosci 10:701-712. CrossRef Medline

Sans N, Petralia RS, Wang YX, Blahos J, Hell JW, Wenthold RJ (2000) A developmental change in NMDA receptor-associated proteins at hippocampal synapses. J Neurosci Res 20:1260. Medline

Schlüter OM, Xu W, Malenka RC (2006) Alternative N-terminal domains of PSD-95 and SAP97 govern activity-dependent regulation of synaptic AMPA receptor function. Neuron 51:99-111. CrossRef Medline

Schnell E, Sizemore M, Karimzadegan S, Chen L, Bredt DS, Nicoll RA (2002) Direct interactions between PSD-95 and stargazin control synaptic AMPA receptor number. Proc Natl Acad Sci U S A 99:13902-13907. CrossRef Medline
Sheng M, Kim MJ (2002) Postsynaptic signaling and plasticity mechanisms. Science 298:776-780. CrossRef Medline

Shevchenko A, Jensen ON, Podtelejnikov AV, Sagliocco F, Wilm M, Vorm O, Mortensen P, Shevchenko A, Boucherie H, Mann M (1996) Linking genome and proteome by mass spectrometry: large-scale identification of yeast proteins from two dimensional gels. Proc Natl Acad Sci U S A 93: 14440-14445. CrossRef Medline

Stein V, House DR, Bredt DS, Nicoll RA (2003) Postsynaptic density-95 mimics and occludes hippocampal long-term potentiation and enhances long-term depression. J Neurosci 23:5503-5506. Medline

Stoppini L, Buchs PA, Muller D (1991) A simple method for organotypic cultures of nervous tissue. J Neurosci Res 37:173-182. CrossRef

Swartz ME, Eberhart J, Pasquale EB, Krull CE (2001) EphA4/ephrin-A5 interactions in muscle precursor cell migration in the avian forelimb. Development 128:4669-4680. Medline

Tao YX, Rumbaugh G, Wang GD, Petralia RS, Zhao C, Kauer FW, Tao F, Zhuo M, Wenthold RJ, Raja SN, Huganir RL, Bredt DS, Johns RA (2003) Impaired NMDA receptor-mediated postsynaptic function and blunted NMDA receptor-dependent persistent pain in mice lacking postsynaptic density-93 protein. J Neurosci 23:6703-6712. Medline

Turrigiano GG, Leslie KR, Desai NS, Rutherford LC, Nelson SB (1998) Activity-dependent scaling of quantal amplitude in neocortical neurons. Nature 391:892-896. CrossRef Medline

Xu W, Schlüter OM, Steiner P, Czervionke BL, Sabatini B, Malenka RC (2008) Molecular dissociation of the role of PSD-95 in regulating synaptic strength and LTD. Neuron 57:248-262. CrossRef Medline

Yoshii A, Sheng MH, Constantine-Paton M (2003) Eye opening induces a rapid dendritic localization of PSD-95 in central visual neurons. Proc Natl Acad Sci U S A 100:1334-1339. CrossRef Medline 